\title{
Sensory nerve supports epithelial stem cell function in healing of corneal epithelium in mice: the role of trigeminal nerve transient receptor potential vanilloid 4
}

\author{
Yuka Okada ${ }^{1}$ Takayoshi Sumioka ${ }^{1} \cdot K_{\text {Kana Ichikawa }}{ }^{1} \cdot$ Hiromi Sano $^{2} \cdot$ Atsushi Nambu $^{2} \cdot$ Kenta Kobayashi $^{3}$. \\ Kunitoshi Uchida ${ }^{4,5} \cdot$ Yoshiro Suzuki $^{4,5} \cdot$ Makoto Tominaga $^{4,5} \cdot$ Peter Sol Reinach $^{6}$ - Syu-ichi Hirai ${ }^{7}$. James V. Jester ${ }^{8}$. \\ Masayasu Miyajima ${ }^{1} \cdot$ Kumi Shirai $^{1} \cdot$ Hiroki Iwanishi $^{1} \cdot$ Winston Whei-Yang Kao ${ }^{9}$. Chia-Yang Liu $^{10} \cdot$ Shizuya Saika $^{1}$
}

Received: 13 June 2018 / Revised: 6 July 2018 / Accepted: 9 July 2018 / Published online: 9 November 2018

(c) United States \& Canadian Academy of Pathology 2018

\begin{abstract}
In order to understand the pathobiology of neurotrophic keratopathy, we established a mouse model by coagulating the first branch of the trigeminal nerve (V1 nerve). In our model, the sensory nerve in the central cornea disappeared and remaining fibers were sparse in the peripheral limbal region. Impaired corneal epithelial healing in the mouse model was associated with suppression of both cell proliferation and expression of stem cell markers in peripheral/limbal epithelium as well as a reduction of transient receptor potential vanilloid 4 (TRPV4) expression in tissue. TRPV4 gene knockout also suppressed epithelial repair in mouse cornea, although it did not seem to directly modulate migration of epithelium. In a co-culture experiment, TRPV4-introduced KO trigeminal ganglion upregulated nerve growth factor (NGF) in cultured corneal epithelial cells, but ganglion with a control vector did not. TRPV4 gene introduction into a damaged V1 nerve rescues the impairment of epithelial healing in association with partial recovery of the stem/progenitor cell markers and upregulation of cell proliferation and of NGF expression in the peripheral/limbal epithelium. Gene transfer of TRPV4 did not accelerate the regeneration of nerve fibers. Sensory nerve TRPV4 is critical to maintain stemness of peripheral/limbal basal cells, and is one of the major mechanisms of homeostasis maintenance of corneal epithelium.
\end{abstract}

\section{Introduction}

Integrity of corneal epithelium is essential to maintain proper vision by serving as a barrier against external stimuli

Electronic supplementary material The online version of this article (https://doi.org/10.1038/s41374-018-0118-4) contains supplementary material, which is available to authorized users.

Shizuya Saika

shizuya@wakayama-med.ac.jp

1 Department of Ophthalmology, Wakayama Medical University School of Medicine, Wakayama, Japan

2 Division of System Neurophysiology, National Institute for Physiological Sciences, Okazaki, Japan

3 Section of Viral Vector Development, National Institute for Physiological Sciences, Okazaki, Japan

4 Division of Cell Signaling, National Institute for Physiological Sciences, Okazaki, Japan

5 Department of Physiological Sciences, SOKENDAI (The such as mechanical or chemical injury or infection by microorganisms. Rapid healing of an epithelial defect in the cornea is critical for the avoidance of infection and further damage to the underlying tissue. Cell migration and proliferation are both the main components of the process of corneal epithelial wound healing [1-3]. Healthy stem cells that locate to the basal layer of the limbal zone (around the periphery of the cornea) play an important role in providing daughter cells to the corneal epithelium for its repair [4, 5].

Graduate University for Advanced Studies), Okazaki, Japan

6 Wenzhou Medical University School of Ophthalmology and Optometry, Wenzhou, China

7 Educational Phyilosophy/Cell Biology, Wakayama Medical University School of Medicine, Wakayama, Japan

8 Department of Ophthalmology, School of Medicine, University of California, Irvine, Irvine, CA, USA

9 Department of Ophthalmology, University of Cincinnati School of Medicine, Cincinnati, OH, USA

10 School of Optometry, Indiana University Bloomington, Bloomington, IN, USA 
Various growth factors are believed to orchestrate the epithelial cell behaviors during tissue repair [1-3]. Among them, nerve growth factor (NGF) and its receptors, p75 and TrkA, are reportedly involved in maintenance of stemness of limbal basal cells with high proliferating potential [6-9].

The cornea is one of the most densely innervated tissues with ophthalmic sensory terminal branches of the trigeminal nerve [10-13]. Nerve fibers enter the limbus and the peripheral cornea and distribute over the cornea in a radial pattern. Then, the fibers penetrate the Bowman's membrane upward and distribute beneath epithelial basal cells, forming the sub-basal nerve plexus that supplies the overlying corneal epithelium [10, 14]. Interaction between sensory nerve and local tissues, i.e., skin or epithelia of internal organs, is required for the homeostasis of the tissue [15-20]. Healthy innervation is essential to the maintenance of corneal structure and function, i.e., barrier function, proliferation, differentiation or wound healing. In turn, impaired sensory innervation or function may impair homeostasis of the corneal epithelium, leading to persistent disorders or abnormal repair in the tissue (neurotrophic keratopathy) [21-23]. It was reported that sensory innervation plays an important role in maintenance of stemness of limbal basal epithelial cells by expressing ATP-binding cassette subfamily G member 2 (ABCG2), p63 and hairy enhancer of split 1 (Hes1), a Notch signal-related component [24]. The causes of impaired trigeminal sensation include direct injury to the intracranial trigeminal nerve by brain trauma or tumor, diabetes mellitus, herpes virus infection or injury in the sensory nerve fibers in the corneal tissue by trauma or surgery such as corneal refractive surgery [25-29]. Although the causes of neurotrophic keratopathy are evident in many cases, neurotrophic keratopathy is refractory to classical treatments, which include wearing a bandage contact lens, tarsorrhaphy or supplementation with an artificial tear solution [30-32]. Refractory persistent corneal epithelial neurotrophic keratopathy could lead to corneal stromal perforation, with or without intraocular infection, that could potentially cause widespread destruction of eye tissue and permanent severe vision loss. Sosne et al. [33] reported the potential efficacy of thymosin $\beta 4$ in the treatment of this condition. The notion that neuropeptides could have a promoting effect on epithelial healing in the cornea was first proposed by Nishida and Yanai [34]. They reported that topical application of a combination of peptides derived from insulin-like growth factor and substance $P$ exerts a significant therapeutic effect on refractory corneal epithelial disorders of neurotrophic keratopathy, but this treatment is not yet clinically available [35]. Recently, it is widely accepted that neuropeptides secreted from sensory nerves are now believed to be involved in the process of tissue repair in organs [36].
One of the presumed reasons why there is currently no effective therapy for neurotrophic keratopathy might be the fact that a suitable experimental mouse model is not available. Ferrari et al. [37] developed a trigeminal stereotactic electrolysis model of clinical neurotrophic keratitis and found that corneal denervation by this procedure resulted in breakdown of the integrity of corneal epithelium and was associated with increased apoptosis and reduced proliferation of epithelial cells. We obtained a similar result by employing a procedure with stereotactic intracranial coagulation of the first branch of the trigeminal nerve by using an 18-guage needle (supplemental data 1). We herein show that use of a 20-guage needle in the same stereotactic procedure reduced the damage of the first branch of the trigeminal nerve and produced a mouse model of neurotrophic keratopathy more similar to clinical cases. This mouse model of neurotrophic keratopathy exhibits a normallooking cornea without obvious tissue inflammation under physiological conditions, but impairment of epithelial wound healing is apparent upon epithelial debridement. Our detailed analysis showed delayed epithelial healing was attributable to the loss of stemness and cell proliferation caused by sensory denervation in peripheral/limbal epithelium. In the current investigation, we employed this mouse model of neurotrophic keratopathy.

Transient receptor potential (TRP) channels constitute a superfamily of 28 genes that are subdivided into 7 subfamilies, including TRP vanilloid (TRPV) and TRP ankyrin type (TRPA), among others. Each TRP superfamily members is a nonselective cation channel that possesses variable $\mathrm{Ca}^{2+}$ permeability and acts as a sensor to a wide array of inputs, including temperature, pressure, $\mathrm{pH}$ alteration, chemicals and lipids. In skin, many of the TRP family members are expressed in both keratinocytes and in sensory nerve fibers and are involved in sensing and maintaining tissue homeostasis [38]. In the cornea, TRP channel subtypes from different subfamilies are involved in mediating responses to injuries that affect the process of wound healing. We previously reported that the loss of either TRPV1, TRPV4 or TRPA1 attenuates excessive inflammatory fibrogenic reaction in a mouse cornea injured by an alkali exposure, and is minimally dependent on the genotype of inflammatory cells [39-41]. On the other hand, we also previously showed that blockage of TRPV1 activation or TRPV1 gene ablation suppressed healing of defective epithelial animal corneas in association with suppression of expression of substance $\mathrm{P}$ and interleukin-6 (IL-6) [42].

Our mouse model of neurotrophic keratopathy, generated by 20 -guage needle nerve coagulation, showed impaired epithelial healing that was associated with suppression of messenger RNA (mRNA) expression of TRPV4 (and TRPA1 to a lesser extent) in a cornea. TRPV4 was 
previously detected in trigeminal nerve fibers [43, 44]. TRPV4 expression is upregulated in nerve fibers under inflammatory conditions in dental pulp, suggesting the presence of significant roles of nerve TRPV4 in modulation of local tissue inflammation [45]. Our current study also revealed that loss of TRPV4 suppresses epithelial repair in a mouse cornea. We therefore hypothesized that the mouse model of neurotrophic keratopathy could be rescued by introducing TRPV4 gene to the damaged sensory nerve. Indeed, TRPV4 gene introduction to the trigeminal nerve rescues the nerve damage-induced impairment of epithelial healing in association with upregulation of NGF expression and cell proliferation of the stem cell region with partial recovery of stem/progenitor cell markers in the peripheral/ limbal epithelium.

\section{Materials and methods}

Protocols in each experiment and the use of mice were all approved by the DNA Recombination Experiment Committee and the Animal Care and Use Committee of Wakayama Medical University and conducted in accordance with the Association for Research in Vision and Ophthalmology Statement for the Use of Animals in Ophthalmic and Vision Research.

\section{Healing of an epithelial defect in in vivo mouse cornea}

Under general and topical anesthesia, a round epithelial defect $2.0 \mathrm{~mm}$ in diameter was produced in the central cornea of the right eye of a mouse using a skin biopsy trephine and microsurgical blade in each experiment as previously reported $[42,46]$. At specific intervals during the healing process, each cornea was processed for evaluation of the epithelial defect closure, gene expression analysis by real-time reverse transcription-polymerase chain reaction (RT-PCR) or 5-bromo-2'-deoxyuridine (BrdU) cell proliferation assay in the epithelium. Epithelial closure of the cornea was evaluated by measuring the size of green fluorescein stain of the defect of the epithelium as previously reported [47].

\section{Immunohistochemistry in paraffin sections}

Immunohistochemistry for TRPV4, ABCG2, Hes1 and proNGF was carried out in uninjured wild-type (WT; $n=4$ ) mouse corneas as well as those of experimental mouse models after post-epithelial debridement as previously reported [39]. Antibodies used were as follows: rabbit polyclonal anti-TRPV4 antibody (Alomone Labs, Jerusalem, Israel, 1:200 in phosphate-buffered saline (PBS)), rabbit polyclonal anti-BCRP/ABCG2 antibody (EPR20080) (ABCAM, ab207732, 1:100 in PBS), rabbit polyclonal antiHes1 antibody (E-5) (Santa Cruz Biotechnology, Inc., sc166410, 1:100 in PBS) and rabbit polyclonal anti-pro-NGF antibody (Alomone Labs).

\section{Cell proliferation assay in the epithelium by BrdU incorporation}

Mice received an intraperitoneal injection of $\mathrm{BrdU}$ (120 $\mu \mathrm{g} / \mathrm{g}$ body weight; Sigma, St. Louis, MO) at specific intervals post debridement, and were killed $2 \mathrm{~h}$ later. At each time point post treatment, the eyes were processed for immunohistochemistry for BrdU as previously reported [46]. The numbers of BrdU-labeled epithelial cells were counted in the $2 \mathrm{~mm}$ central diameter and designated as "the BrdU, central cornea", and in the area outside this $2 \mathrm{~mm}$ are as "the BrdU, peripheral/limbal cornea". Eight eyes of each genotype (WT or knockout (KO)) were used at each time point (12, 24 or $36 \mathrm{~h}$ post wounding), and 3 eyes for at 12 and at $24 \mathrm{~h}$ for the control adeno-associated virus (AAV) and TRPV4-AAV groups.

\section{Gene expression in cornea after injury}

Gene expression analysis in cornea was performed by using real-time RT-PCR as previously reported [38]. Each cornea was processed for total RNA extraction with a Sigma kit (Sigma, \#RTN70). Four corneas served as one sample of RNA in each experiment. TaqMan real-time RT-PCR was carried out as previously reported using Applied Biosystems Gene Expression Assays (delta/delta CT analysis). All the data were normalized for endogenous expression of glyceraldehyde 3-phosphate dehydrogenase (GAPDH), and were statistically analyzed using Mann-Whitney $U$ test. Primers used are shown in Table 1.

Table 1 The primer list of real time RT-PCR

\begin{tabular}{ll}
\hline TRPV1: & Mm 01246302_ml \\
TRPV4: & Mm 00499025_ml \\
TRPA1: & Mm01227437_ml \\
SP: & Mm01166996_ml \\
CGRP: & Mm00801463_g1 \\
NGF: & Mm00443039_m1 \\
IL-6: & Mm01210732_gl \\
TGF $\beta 1:$ & Mm03024053_ml \\
GAPDH: & Mm03302249_gl \\
\hline
\end{tabular}




\section{Stereotactic coagulation of the first branch of the intracranial trigeminal nerve}

The first branch of the right intracranial trigeminal nerve was located by observation of the dissected mouse head. The nerve tissue suitable for the coagulation was located $6.0 \mathrm{~mm}$ from the cranium at the point shown in Fig. 1. After skin incision, a small hole was produced in the cranium using a needle at the point described above, a bipolar coagulation (either 18-guage or 20-guage, Beaver-Visitec International Inc.: 221260) was inserted into the brain to a depth of $6.0 \mathrm{~mm}$. The nerve was coagulated for $3 \mathrm{~min}$ with a coagulator machine (OPTIKON $2000^{\circ}$ Model: P4000, 2 $\mathrm{MHz}, 13 \mathrm{~W}, 250 \Omega$ ). Sensory loss was confirmed by the lack of the blink reflex on air jet stimulation as well as by confirming less response with cochet-bonnet aesthesiometer. We confirmed that the first branch of the trigeminal nerve was precisely coagulated by direct observation of the treated intracranial nerve and histology. Intact or coagulated trigeminal nerve at day $7(n=3)$ was fixed in $4 \%$ paraformaldehyde (PFA) in $0.1 \mathrm{M}$ phosphate buffer ( $\mathrm{pH}$ 7.4) for $24 \mathrm{~h}$, embedded in paraffin and then processed for histology. Paraffin sections $(5 \mu \mathrm{m})$ of specimens were processed for hematoxylin and eosin (HE) staining and Kluver-Barrera (KB) staining. The histology showed that the tissue showed demyelination or nerve tissue destruction.

Evaluation of corneal epithelial wound healing was performed as follows: at 3 months after stereotactic 20guage needle coagulation of the first branch of right trigeminal nerve, mice $(n=6)$ were used for the epithelial wound healing assay as described above. Six normal corneas served as controls. Epithelial healing was observed at up to $30 \mathrm{~h}$. Forty corneas of 40 trigeminal denervated mice and 40 control corneas also received epithelial injury and allowed to heal for $18 \mathrm{~h}$. These samples were processed for RNA extraction for real-time RT-PCR.

\section{Migration of cultured corneal epithelial cells in the presence of an antagonist for TRPV4}

In order to determine if signals derived from TRPV4 receptor modulate migration of corneal epithelial cells, we conducted a scratch assay in monolayer cultures of TKE2 corneal epithelial cell line as previously reported [48]. The cells were cultured in a medium with specific supplements for the cell type (keratinocyto-serum free medium: Gibco \#17005-042). A liner defect was produced in monolayer culture of the cells in a 6-well plate in the medium without the specific supplements using a silicone needle. Four lines were produced in two wells in each culture condition. Effects of adding an antagonist for TRPV4 (HC-67047: 1 $\mu \mathrm{M}$ in dimethyl sulfoxide (DMSO)) on the closure of the scratch were observed. The $1 \mu \mathrm{M}$ DMSO culture served as control. The defect was photographed and the width of the defect was determined at every $12 \mathrm{~h}$. Data were analyzed by Mann-Whitney $U$ test.

\section{Organ culture for evaluation of epithelial wound healing in cornea with inhibition of TRPV4 signal}

Two systems of organ culture were employed. First, we performed organ culture of a tissue block obtained from a mouse as previously reported $[47,49]$ with a minor modification. A rectangular sample excised from a mouse cornea was placed in an organ culture system in Eagle's minimum essential medium. WT $(n=8)$ mice and TRPV4null (KO, RIKEN, Tokyo, Japan) $[50,51]$ mice $(n=8)$ were employed. The blocks from WT mice were cultured in the presence or absence of a TRPV4 inhibitor (HC-67047: $1 \mu \mathrm{M}$ in DMSO). At $12 \mathrm{~h}$ of culture, the blocks were fixed with $4 \%$ PFA, embedded in paraffin, cut in sections and processed for HE staining. The length of the epithelial path on the stromal cut surface was measured. The average on both sides represents epithelial migration in one block. The mean data from each condition were analyzed using Mann-Whitney $U$ test.

To determine the role of TRPV4 channel in epithelial defect healing in cornea, we then conducted an organ culture of a mouse eye with a round epithelial defect as previously reported. [42] Under both general anesthesia and topical anesthesia, a round epithelial defect $(2.0 \mathrm{~mm}$ in diameter) was produced in the same way as in in vivo experiments as described above for the 40 corneas. The mice were killed without re-awaking and the eye globe was enucleated. The eyes with an epithelial debridement were then placed in an organ culture in Eagle's medium supplemented with $2.0 \%$ fetal bovine serum with or without HC-067047. The re-epithelialization of the defect was determined by fluorescein staining after 12, 24 and $36 \mathrm{~h}$ of culture. Five eyes were prepared for each experimental condition at each time point. Each cornea was photographed with green fluorescein staining in order to observe the size of the remaining defect in the epithelium.

The epithelium-debrided corneas incubated for 1 and 36 $\mathrm{h}$ were immunostained for Tuj1 in order to observe the distribution and configuration of nerve fibers as described below in detail.

\section{Healing of an epithelial defect in an in vivo KO mouse cornea}

A set of 8-week-old C57BL/6 (WT, $n=6)$ and KO $(n=6)$ mice of C57BL/6 background that received an epithelial debridement in the central cornea of the right eye were allowed to heal for up to $30 \mathrm{~h}$ for evaluation of healing as described above. 
A

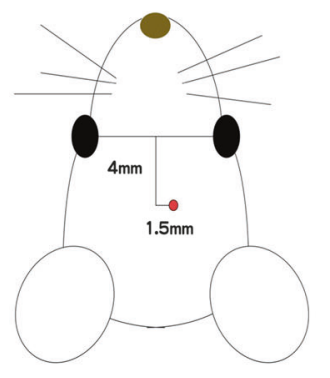

D

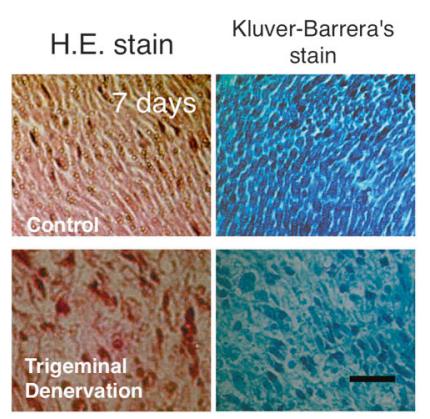

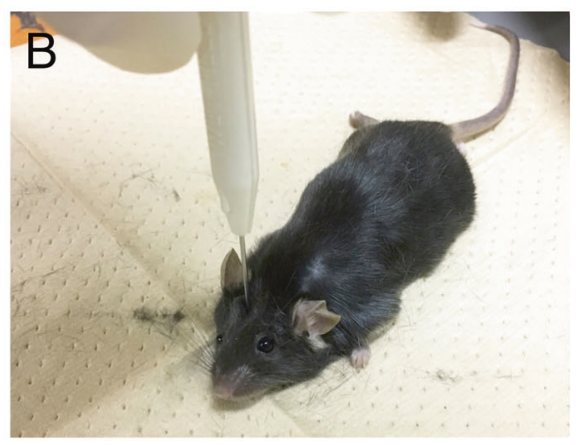
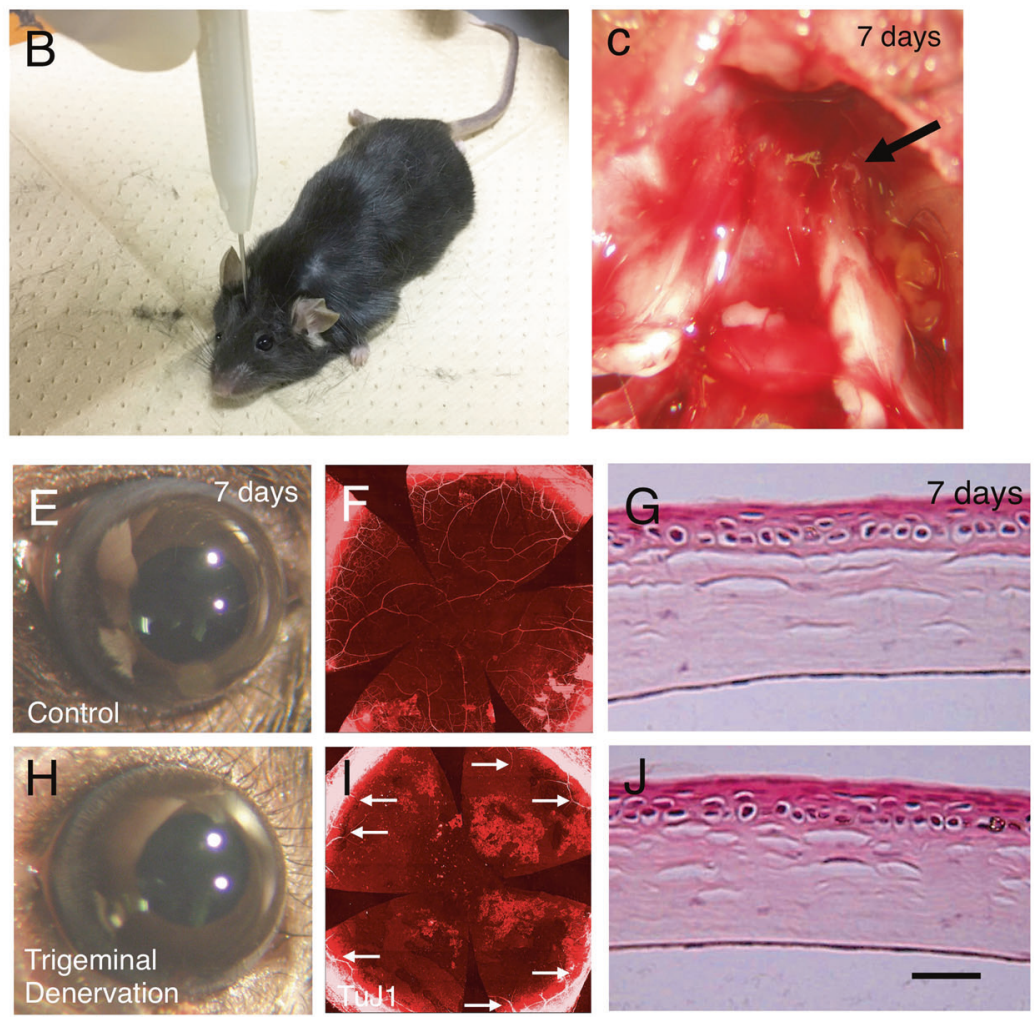

nerve fibers in the cornea in a whole-mounted specimen. In a cornea of an untreated mouse nerve fibers were distributed in a whole cornea (f), while Tuj1-labeled fibers were observed only in the limbus and the peripheral (arrows), but not in the majority of the area, area of the cornea of a treated mouse (i). Density of the nerve fiber in the peripheral/limbal area was much less in the eye with intracranial V1 nerve coagulation as compared with a control eye. $\mathbf{g}$, j Hematoxylin and eosin histology showed that the current procedure of stereotactic electrolysis with a 20-guage needle did not affect the structure of cornea and cell population in it at light microscopic level up to 10 months after the treatment. Scale bar: $100 \mu \mathrm{m}$. j Comparison with a healthy cornea $(\mathbf{g})$

epithelial cell. TKE2 corneal epithelial cell line was cultured until reaching confluent in the lower well. The AAV vectors were prepared using AAV Helper Free Package system (Cell Biolabs, Inc., San Diego, CA) as described previously [52]. The AAV vector carrying mTRPV4-DsRed (AAV2-CAGGS-mTRPV4-DsRed, titer; $1.8-5.8 \times 10^{7} \mathrm{vg} /$ $\mathrm{ml}$ ) or DsRed transgene (AAV2-CAGGS-DsRed, titer; $9.3 \times 10^{9} \mathrm{vg} / \mathrm{ml}$ ) was injected into first branch of trigeminal nerve of mice by a glass micropipette connected to a microsyringe and microinfusion pump (Micro4, World Precision Instruments, Sarasota, FL, $0.5 \mu \mathrm{l}$ at a rate of $0.1 \mu \mathrm{l} /$ min). A trigeminal ganglion of $\mathrm{KO}$ mice either treated with in vivo gene transfer of TRPV4-AAV $(n=6)$ or control AAV $(n=6)$ was placed in the upper well. The co-culture sets were prepared for each culture condition. mRNA 
expression of TRPV4, NGF and calcitonin gene-related peptide (CGRP) in the cells in the lower well was assayed using real-time RT-PCR.

\section{Primary culture of cells from a mouse trigeminal ganglion}

Primary culture of trigeminal ganglion cells was prepared according to a method described elsewhere [53] with a minor modification: Trigeminal ganglia of a postnatal day 10 mouse was dissected, washed with ice-cold Dulbecco's modified Eagle's medium (DMEM)/F12, and enzymatically digested with $0.1 \%$ collagenase (Type I, Sigma, \#C0130)/ DMEM/F12 for $30 \mathrm{~min}$ at $37{ }^{\circ} \mathrm{C}$ and then with $0.05 \%$ trypsin/EDTA-HBS (Invitrogen, \#25300-054) for $40 \mathrm{~min}$ at $37^{\circ} \mathrm{C}$. The digested ganglia were washed once with DMEM/F12 supplemented with $10 \%$ fetal calf serum and triturated with fire polished glass pipettes. The cell suspension was centrifuged at $2000 \mathrm{rpm}$ for $2 \mathrm{~min}$, and cells were re-suspended in DMEM/F12 supplemented with $10 \%$ fetal calf serum and cultured on $60 \mathrm{~mm}$ dish $\left(\sim 4.0 \times 10^{5}\right.$ cells). The next day, cells were treated with $3 \mu \mathrm{g} / \mathrm{ml}$ of mitomycin $\mathrm{C}$ for $2 \mathrm{~h}$, washed twice with PBS and cultured for another 4 days with AAVDJ-CAGGS-mTRPV4-DsRed $\left(1.3 \times 10^{6} \mathrm{vg} / \mu \mathrm{l}\right)$ or AAVDJ-CAGGS-DsRed $\left(4.1 \times 10^{9} \mathrm{vg} /\right.$ $\mu \mathrm{l})[53,54]$ in fresh DMEM/F12 supplemented with $10 \%$ fetal calf serum. Cells were then harvested for RNA preparation or fixed with 3\% PFA/PBS for immunofluorescent microscopy.

\section{TRPV4 gene transfer to the trigeminal nerve and in vivo epithelial wound healing}

Mice were anesthetized with ketamine hydrochloride (100 $\mathrm{mg} / \mathrm{kg}$, intraperitoneally (i.p.)) and xylazine hydrochloride $(5 \mathrm{mg} / \mathrm{kg}$, i.p.) or pentobarbital ( $90 \mathrm{mg} / \mathrm{kg}$, i.p.). The head of the mouse was fixed to the stereotactic apparatus (Narishige, Tokyo, Japan).

The AAV vector mentioned above carrying mTRPV4DsRed (AAV2-CAGGS-mTRPV4-DsRed, titer; 1.8-5.8 × $10^{7} \mathrm{vg} / \mathrm{ml}$ ) or DsRed transgene (AAV2-CAGGS-DsRed, titer; $9.3 \times 10^{9} \mathrm{vg} / \mathrm{ml}$ ) was injected into first branch of trigeminal nerve of mice by a glass micropipette as described above. Following two sets of experiments were performed.

First, we examined if TRPV4 gene transfer to the nerve rescues an impairment of corneal epithelial helaing in a $\mathrm{KO}$ mouse. KO mice received either TRPV4-AAV $(n=4)$ or control $\operatorname{AAV}(n=4)$. At 4 weeks after gene transfer, the mice received a round epithelial debridement and was allowed to heal up to $36 \mathrm{~h}$ for examination of epithelial repair as described above. The corneas were also processed for whole-mount immunostaining for TRPV4 or Tuj1 as described below.
We then examined if TRPV4 gene transfer to the nerve rescues an impairment of corneal epithelial healing by trigeminal ophthalmic nerve damage. Mice with right trigeminal coagulation also received TRPV4-AAV $(n=5)$ or control AAV $(n=4)$ in the damaged nerve as described above, and then epithelial debridement healing was monitored as described above. In another series, WT mice with trigeminal nerve treatment with either AAV-TRPV4 gene transfer of control gene transfer were administered BrdU at $12 \mathrm{~h}(n=4)$ and $24 \mathrm{~h}(n=6)$ post debridement for examination of epithelial cell proliferation. Finally, the trigeminal denervated mice received TRPV4-AAV $(n=10)$ or control $\operatorname{AAV}(n=9)$ and then received a round epithelial debridement. At $12 \mathrm{~h}$ after debridement the cornea was processed for RNA extraction and real-time RT-PCR for NGF, CGRP and TRPV4 as described above.

\section{Whole-mount observation of a mouse cornea}

The cornea of a mouse 8 months after stereotaxic 20-guage needle coagulation of the first branch of right trigeminal nerve was obtained after confirming the transparency of the cornea and impairment of the blink after air jet stimulation $(n=8)$. The tissue was fixed in $4 \%$ PFA in $0.1 \mathrm{M}$ phosphate buffer and processed for TuJ1 immunostaining. The fixed corneas were carefully cut into a clover leaf shape and incubated in $0.2 \%$ sodium borohydride in PBS for $1 \mathrm{~h}$ at room temperature. After 3 washes with PBS, the corneas were incubated in $2 \mathrm{~N} \mathrm{HCl}, 0.5 \%$ Triton $\mathrm{X}-100^{\circ}$ in PBS for $1 \mathrm{~h}$ at room temperature. After 1 wash with $0.1 \mathrm{M}$ phosphate buffer ( $\mathrm{pH}$ 7.4) and 2 washes with PBS, the corneas were incubated in $1 \mathrm{mg} / \mathrm{ml}$ bovine serum albumin in $50 \% \mathrm{TD}$ (0.5\% DMSO, $0.5 \%$ Triton $\mathrm{X}-100^{\circ}$ and $2.5 \%$ dextran 40 in PBS) for $15 \mathrm{~min}$ at room temperature, and anti-neuronal class III b-tubulin (Tuj1) antibody (1:500, Covance, Alice, $\mathrm{TX}$ ) for $24 \mathrm{~h}$ at $4{ }^{\circ} \mathrm{C}$. After washing 2 times with $50 \% \mathrm{TD}$ and PBS, the corneas were incubated with fluorescein isothiocyanate (FITC)-conjugated secondary antibody overnight at $4{ }^{\circ} \mathrm{C}$ and then washed thoroughly with PBS. Corneas excised from freshly enucleated eyes were also processed in the same way as described above to obtain a control finding. The samples were observed under ApoTome2 (Zeiss) or EVOS FL Auto Cell Imaging System (Invitrogen-ThermoFisher Scientific).

Trigeminal nerve coagulation corneas with TRPV4-AAV gene transfer received epithelia $(n=5)$, debridement and were allowed to heal for $12 \mathrm{~h}$. The specimens were also processed for whole-mount observation for DsRed of AAV vector and Tuj1 (with FITC-conjugated secondary antibody). TRPV4-null mice that had received either TRPV4AAV or control AAV in the trigeminal nerve were processed for whole-mount immunostaining for TRPV4 (with FITC-conjugated secondary antibody). 


\section{Results}

\section{A mouse model of neurotrophic keratopathy}

Stereotactic electrolysis of the first branch of the right trigeminal nerve was performed using a 20-guage bipolar coagulator needle (Fig. 1a, b, $6.0 \mathrm{~mm}$ in depth of the needle insertion) in a C57BL/6 mouse under general anesthesia. To confirm the tissue coagulation in the first branch of the trigeminal nerve, we macroscopically observed the intracranial trigeminal nerve branches and histologically analyzed the nerve tissue in a preliminary series of mice. Figure 1c shows the gross appearance of the coagulated tissue in the trigeminal nerve. Light microscopy with HE staining and $\mathrm{KB}$ stain revealed destruction of nerve fibers in the coagulated area of the trigeminal nerve branch (Fig. 1d). In contrast to the eye treated with an 18-guage needle (supplemental data), the gross appearance of cornea after the 20-guage needle treatment did not show abnormality under physiological uninjured conditions at day 7 without tarsoraphy (Fig. 1e-h). The loss of the blink reflex on air jet stimulation was observed on the day 1 after nerve coagulation, which was the indication of sensory loss as previously reported [37]. Immunodetection of TuJ1 revealed reduced innervation in the treated cornea as compared to an untreated cornea (Fig. 1f-i). Tuj1-labeled nerve fibers were observed in the entire cornea of an untreated mouse, while nerve fibers were sparsely observed in the peripheral and limbus areas, but not in the central area, of the cornea of a treated mouse. Density of the nerve fiber in the peripheral/ limbal area was much less in the eye with intracranial V1 nerve coagulation as compared with a control eye. Histology showed that the current procedure of stereotactic electrolysis with a 20-guage needle did not impact the structure of cornea and did not induce obvious inflammation at the light microscopic level for up to 10 months after the treatment (Fig. 1g-j). In this study, the 20 -guage needle model for the evaluation of epithelial tissue repair.

\section{Wound healing in defective mouse corneal epithelium following trigeminal stereotactic electrolysis}

We examined wound healing in corneal epithelium following round epithelial debridement $[42,46]$ in a mouse with reduced sensory innervation by nerve electrolysis in order to determine whether innervation is critical to tissue repair (Fig. 2a). The results show that denervation of the first branch of the trigeminal nerve retarded closure of an epithelial debridement $2.0 \mathrm{~mm}$ in diameter, with statistical significance at $18 \mathrm{~h}$ post wounding (Fig. 2b). Gene expression analysis by real-time RT-PCR showed that the denervation upregulated mRNA expression of TRPV1 and
NGF in the whole cornea tissue under uninjured condition (Fig. 2c). After $18 \mathrm{~h}$ of healing following epithelial debridement, expression of TRPV1 was suppressed in denervated corneas. Expression of TRPA1, TRPV4, CGRP and NGF was upregulated in the tissue at $18 \mathrm{~h}$ post injury in control corneas (Fig. 2c). However, the upregulation of TRPA1, TRPV4 and NGF was counteracted by the trigeminal denervation at this time point. Upregulation of CGRP was not counteracted by the trigeminal nerve electrolysis. Expression of substance $\mathrm{P}$ and transforming growth factor- $\beta 1$ (TGF $\beta 1$ ) in corneal tissue was unaffected by the trigeminal denervation and also not remarkably changed by wounding (Fig. 2c).

We then examined the protein expression pattern of proNGF in mouse cornea. Pro-NGF was detected in both uninjured and in healing, injured, corneal epithelium of either control or trigeminal denervated cornea. At 12 and $24 \mathrm{~h}$ post epithelial injury, immunohistochemical staining for pro-NGF was less intense in the peripheral/limbal epithelium of a trigeminal denervated mouse compared to a control mouse (Fig. 3a). To examine the cell proliferation activity in the epithelium we performed BrdU immunostaining (Fig. 3b). The number of BrdU-labeled epithelial cells was determined in histology sections (Fig. 3c). At the zero time point there was no significant difference of BrdUlabeled epithelial cells in the central (central $2 \mathrm{~mm}$ in diameter) and peripheral/limbal (outside the central circle) epithelia in both control and trigeminal denervated mice. At $12 \mathrm{~h}$ post wounding, proliferating cells in the peripheral/ limbal epithelium were more frequently observed in the control mouse as compared to the denervated mouse. At 24 $\mathrm{h}$ post debridement, BrdU-labeled cells in either central or peripheral/limbal epithelium were more frequently observed in the control mouse as compared to the trigeminal denervated mouse.

\section{Scratch assay in a cultured corneal epithelial cell line}

A scratch assay was performed to evaluate the effect of a TRPV4 antagonist on migration of TKE2 corneal epithelial cells, as previously reported [48]. Closure of a liner defect in the cell monolayer was not affected by addition of an antagonist for TRPV4 (HC-067047,1 $\mu \mathrm{M}$ ) (Fig. 4a). The TRPV4 antagonist HC-067047 did not exert a significant effect on the closure of the defect in cell culture, suggesting TRPV4 signaling did not play a critical role in modulation of epithelial cell movement (Fig. 4b).

\section{Organ culture experiments}

To examine epithelial spreading on corneal tissue, organ culture of an excised corneal block was performed as previously reported [47]. Downward spreading of an epithelial 
A
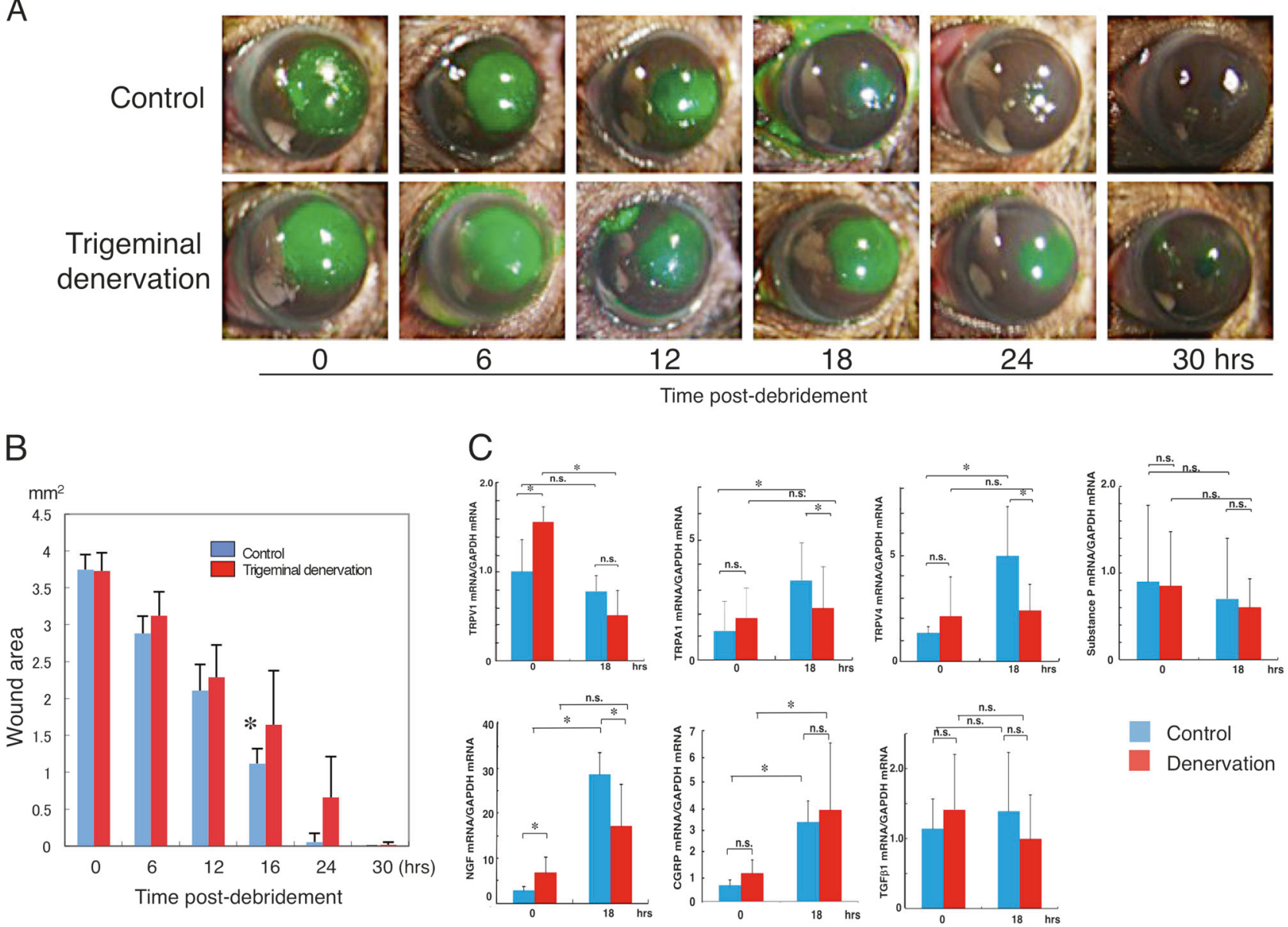

Control

Denervation

Fig. 2 Wound healing of corneal epithelium in a mouse following trigeminal stereotactic electrolysis. a A round epithelial defect $(2.0 \mathrm{~mm}$ in diameter, stained with green fluorescein) was allowed to heal up $30 \mathrm{~h}$. In a healthy mouse the epithelial defect was gradually healed and totally recovered in 24-30 h. On the other hand, the cornea of a mouse following electrolysis coagulation of the first branch of the trigeminal nerve showed significant delayed epithelial defect closure. Even at $24 \mathrm{~h}$ post debridement, the defect obviously remained, while a minor faint defect was observed in a control cornea. After $30 \mathrm{~h}$, the debridement was closed in the denervated cornea. $\mathbf{b}$ Bar chart of the size of the remaining epithelial defect in the corneal epithelium at each time point. Denervation of the first branch of the trigeminal nerve retarded closure of the epithelial debridement with a statistical significance at $18 \mathrm{~h}$ post wounding $(* P<0.05)$. c Gene expression analysis using realtime reverse transcription-polymerase chain reaction (RT-PCR) was

sheet on the cut surface of the corneal stroma represents migration of the epithelium. In this system, migration of epithelium was not affected by TRPV4 gene deletion and addition of a TRPV4 antagonist (Fig. 4d).

In order to determine the roles of TRPV4 signal in the healing of corneal epithelium in the absence of inflammatory cells, we then observed epithelial healing in an organcultured mouse eye with a round epithelial defect of $2.0 \mathrm{~mm}$ in diameter (Fig. 4e), as previously reported [42]. The experimental system excludes involvement of the loss of TRPV4 in blood-derived cell in tissue repair, while performed to investigate the biological background of the delay of the epithelial healing. The denervation upregulated mRNA expression of TRPV1 and nerve growth factor (NGF) under the uninjured condition. At $18 \mathrm{~h}$ during healing, post-epithelial debridement expression of TRPV1 was suppressed in denervated corneas. On the other hand, expression of TRPA1, TRPV4 and NGF was upregulated in the tissue at $18 \mathrm{~h}$ post wounding in control corneas. However, the upregulation of these three components was significantly counteracted by trigeminal denervation. Expression of calcitonin gene-related peptide (CGRP) was upregulated by epithelial debridement, but is not counteracted by the trigeminal denervation treatment. Expression of substance $\mathrm{P}$ and transforming growth factor- $\beta 1$ (TGF $\beta 1$ ) in corneal tissue was unaffected by trigeminal nerve electrolysis and also not remarkably changed by wounding. Data represent the mean \pm SEM. $* P<0.05$ and $* * P<0.01$ by Mann-Whitney $U$ test $(\mathbf{b}, \mathbf{c})$

epithelial healing is performed in a more physiological condition, i.e., on the basement membrane. A round epithelial defect in a mouse cornea was re-epithelialized in organ culture in $36 \mathrm{~h}$. An antagonist for TRPV4 (HC067047, $1 \mu \mathrm{M}$ ) retarded epithelial defect closure; statistical significance was observed at 12 and $24 \mathrm{~h}$ with a TRPV4 antagonist (Fig. 4f). After $36 \mathrm{~h}$ of culture, whole-mounted immunohistochemistry for Tuj1 was performed in order to detect nerve fibers in the cornea of control cultures, and although the fibers exhibited a somewhat beaded configuration, we have not determined whether the sensory nerve 

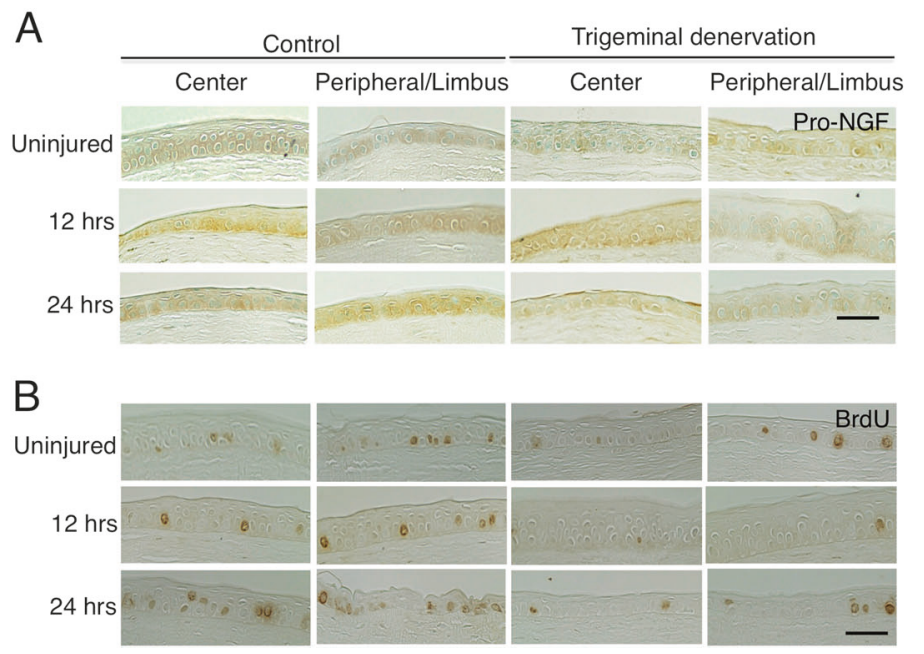

C

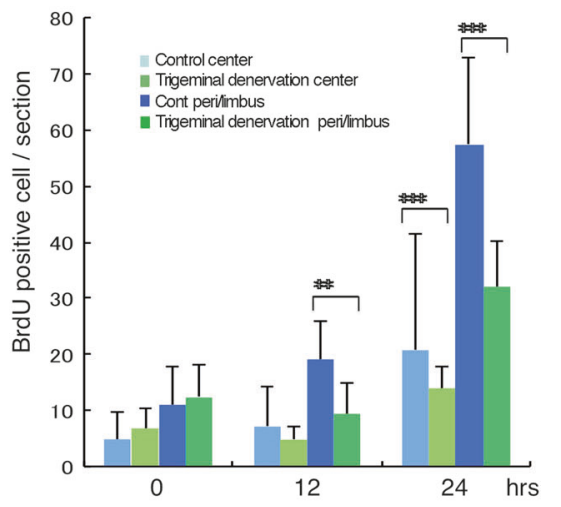

Fig. 3 Protein expression of pro-nerve growth factor (pro-NGF) and cell proliferation activity in healing epithelium of a cornea of a mouse that received coagulation of the first branch of the trigeminal nerve. a An uninjured central epithelium and healing epithelium at 12 and $24 \mathrm{~h}$ post debridement were labeled for pro-NGF. In a healthy mouse, peripheral/limbal epithelium upregulates pro-NGF protein expression upon epithelial injury. Immunolabeling for pro-NGF in peripheral/ limbal epithelium was more intense in a healthy subject as compared to that in a mouse after sensory denervation. Scale bar: $100 \mu \mathrm{m}$. b, c An uninjured central epithelium and healing epithelium at 12 and $24 \mathrm{~h}$

was functionally active, even in the earlier phase of culture (Fig. 4g).

\section{Loss of TRPV4 retards re-epithelialization of debrided mouse cornea in vivo}

TRPV4 was markedly expressed in the basal layer of an uninjured healthy epithelium of the central and peripheral/ limbal epithelia (Fig. 5a). Expression of TRPV4 (and also TRPA1) in the cornea tissue was prominently suppressed by the trigeminal denervation treatment during healing following epithelial debridement as described above. Therefore, we evaluated healing of an epithelial injury in the central cornea of a mouse that lacks the TRPV4 gene to examine the role of signal derived from TRPV4 receptor in re-epithelialization of debrided cornea (Fig. 5b). At 18 and $24 \mathrm{~h}$ post debridement, the defect remaining was larger in either KO mice as compared to WT mice (Fig. 5b, c).

In order to determine the mechanism underlying attenuation of epithelial wound healing by the loss of the TRPV4 channel, we then examined if lack of TRPV4 alters the expression pattern of epithelial wound healing-related components by employing real-time RT-PCR. Our results show that mRNA expression levels of CGRP and TGF $\beta 1$ were downregulated by the loss of the TRPV4 channel at $12 \mathrm{~h}$ post epithelial wounding (Fig. 5d). Expression of NGF was downregulated in an uninjured cornea by the loss of post debridement contain BrdU-labeled proliferating cells. Cell proliferation was upregulated during healing post injury in a healthy control tissue. The number of BrdU-labeled epithelial cells was more frequently observed in peripheral/limbal epithelium at $12 \mathrm{~h}$ post wounding. At $24 \mathrm{~h}$ post debridement, proliferation activity was more marked in both central and peripheral/limbal epithelia in a healthy control mouse as compared to that in a mouse after sensory denervation. Pri/limbus peripheral/limbal epithelium. Scale bar: $100 \mu \mathrm{m}$. Data represent the mean \pm SEM. $* * P<0.01$ and $* * * P<0.005$ by Mann-Whitney $U$ test (c)

TRPV4 (Fig. 5d). mRNA expression of IL-6 and substance $\mathrm{P}$ was unaltered by TRPV4 gene ablation (Fig. 5d).

Immunohistochemistry showed that pro-NGF protein expression was suppressed by the loss of TRPV4 in epithelium in the central cornea and peripheral/limbal cells as compared to a WT mouse (Fig. 6a). Cell proliferation in healing epithelium was evaluated by BrdU detection. The loss of TRPV4 did not affect cell proliferation activity in central corneal epithelium until $12 \mathrm{~h}$ post debridement. After $24 \mathrm{~h}$, cell proliferation was suppressed in $\mathrm{KO}$ mice as compared to WT mice in both central and peripheral/limbal epithelium. The degree of suppression was more prominent in the peripheral/limbus area. At $36 \mathrm{~h}$ after producing the defect, cell proliferation activity was still lower in the KO group as compared to the WT group. Such suppression was not observed in epithelium of the central cornea (Fig. 6b, c).

\section{In vitro effect of TRPV4 overexpression in trigeminal ganglion on gene expression in corneal epithelial cells or ganglion-derived cells}

The findings that sensory denervation in cornea retarded epithelial healing in association with reduced expression of components including TRPV4 and that lack of TRPV4 also its healing promoted us to hypothesize that neural TRPV4 could have an impact on the local epithelium. We then examined whether TRPV4 gene transfer to KO trigeminal 
A
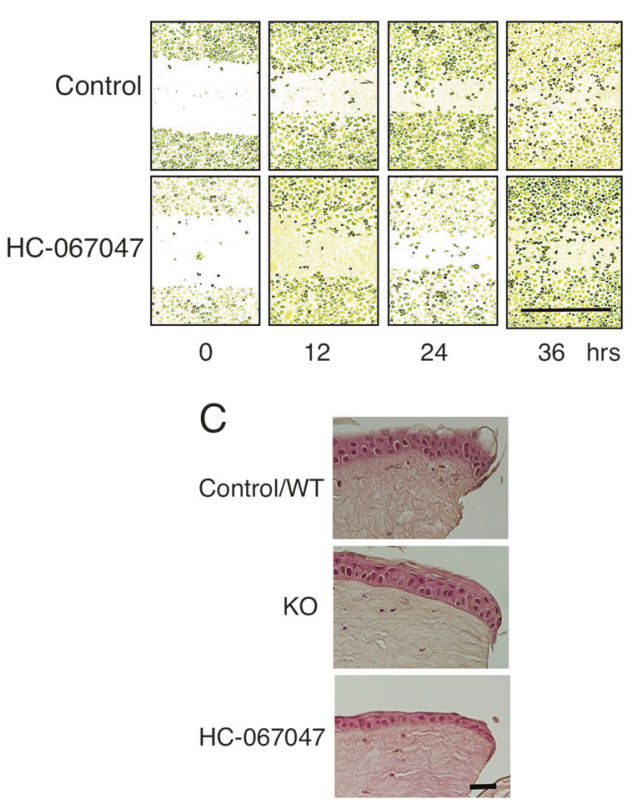

$E$

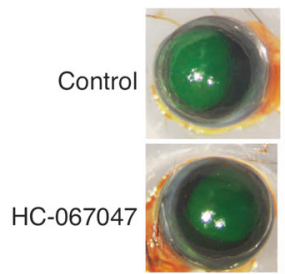

0

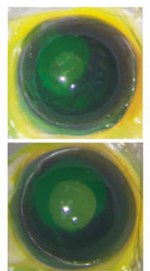

12

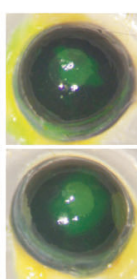

24

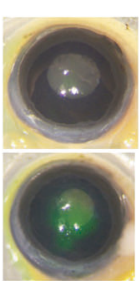

36 hrs
B

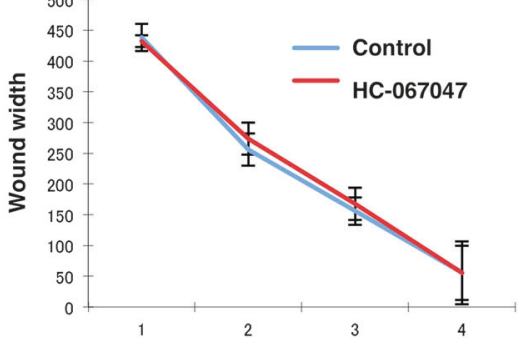

$\mathrm{D}$

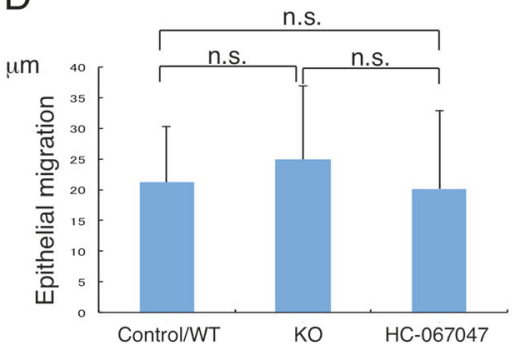

F

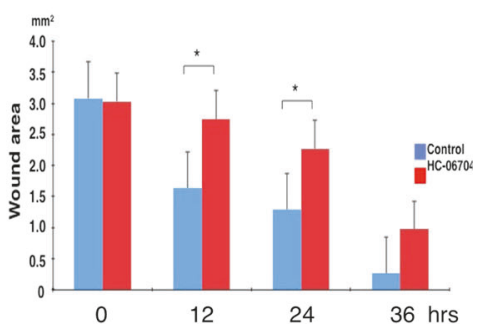

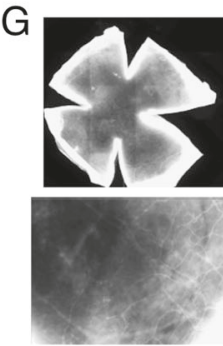

1

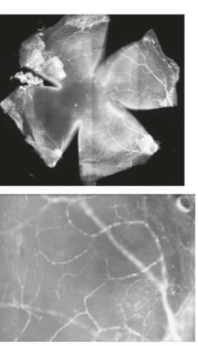

36 hrs

Fig. 4 Cell- or organ-culture experiments for evaluation of the effects of adding an TRPV4 inhibitor on corneal epithelial wound healing. a, b Scratch assay was performed to evaluate the effect of adding a TRPV4 antagonist on migration of TKE2 corneal epithelial cells. Closure of a liner defect in the cell monolayer was not affected by adding an antagonist for TRPV4 (HC-067047 at the concentration of 1 $\mu \mathrm{M})$. This suggests that TRPV4 signal did not have a critical role in cell movement modulation. Scale bar: $500 \mu \mathrm{m}$. c. d Epithelium migrates down on the cut surface of an organ-cultured block of a mouse cornea (arrowheads). The length of the migrating epithelial path was similar among cultured corneal blocks from wild-type (WT) and TRPV4-null (KO) mouse in control medium and that from a WT

ganglion by the AAV vector affects gene expression in cultured corneal epithelial cells in a co-culture system (Fig. 7a, b). Trigeminal nerve ganglion of a KO mouse 4 weeks after treatment with TRPV4-AAV or control AAV as described in the Materials and methods section was excised and placed into a co-culture system. TRPV4 gene transfer to a $\mathrm{KO}$ trigeminal nerve ganglion in the upper well upregulated mRNA expression of TRPV4 (Fig. 7c) and NGF (Fig. 7d) in corneal epithelial cells in the lower culture as compared to control AAV-treated $\mathrm{KO}$ ganglion. There was no statistically significant difference in expression levels of CGRP between the two groups (Fig. 7e).

To examine the effects of overexpression of TRPV4 on gene expression of components of trigeminal ganglion, we

mouse with a TRPV4 inhibitor. Scale bar: $100 \mu \mathrm{m}$. e, f Organ culture of a mouse eye was also conducted to mimic in vivo situation with basement membrane and epithelial structure as well as the presence of keratocytes, but without involvement of inflammatory cells. In this system a round epithelial defect $(2.0 \mathrm{~mm}$ in diameter) in a mouse cornea was re-epithelialized in organ culture in $36 \mathrm{~h}$. Adding an antagonist for TRPV4 (HC-067047) retarded epithelial defect closure; statistical significance was observed at 12 and $24 \mathrm{~h}$. g After a $36 \mathrm{~h}$ culture, whole-mounted immunohistochemistry for Tuj1 detected nerve fibers in the cornea of control culture, although the fibers exhibited a somewhat beaded configuration. Data represent the mean \pm SEM. $* P<0.05$ by Mann-Whitney $U$ test $(\mathbf{b}, \mathbf{d}, \mathbf{f})$

conducted cell culture experiments. Trigeminal ganglion from a WT mouse was dispersed, cultured and processed for TRPV4 gene transfer using an AAV vector (Fig. 7f). The cultures were incubated for $24 \mathrm{~h}$ and then processed for RNA extraction. The results show that expression of CGRP, NGF and substance $P$ in a ganglion-derived culture was unchanged by TRPV4 overexpression (Fig. $7 \mathrm{~g}$ ).

\section{Gene introduction of TRPV4 in intracranial trigeminal nerve rescues impairment of corneal epithelial healing in a $\mathrm{KO}$ mouse}

We hypothesized that global knockout of TRPV4 impairs epithelial healing in a mouse cornea due to the loss of 
A

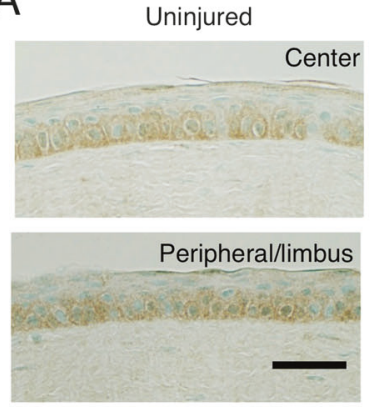

B

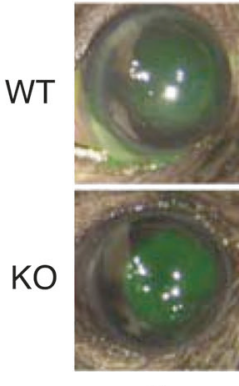

0
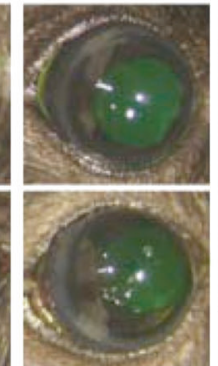

6

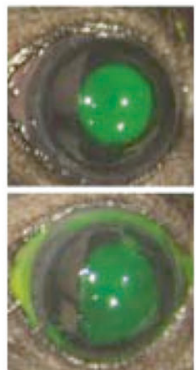

12

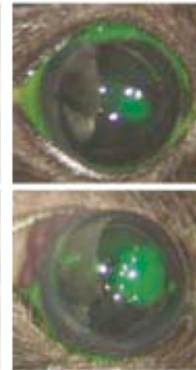

18

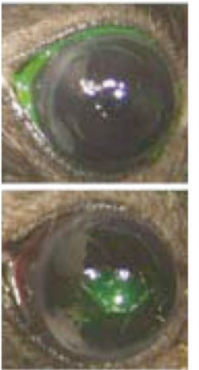

24

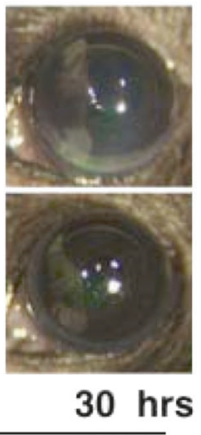

$30 \mathrm{hrs}$

Time post-debridement

C

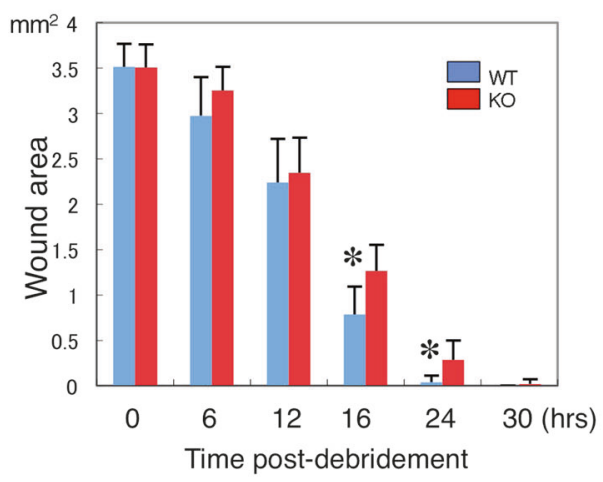

D
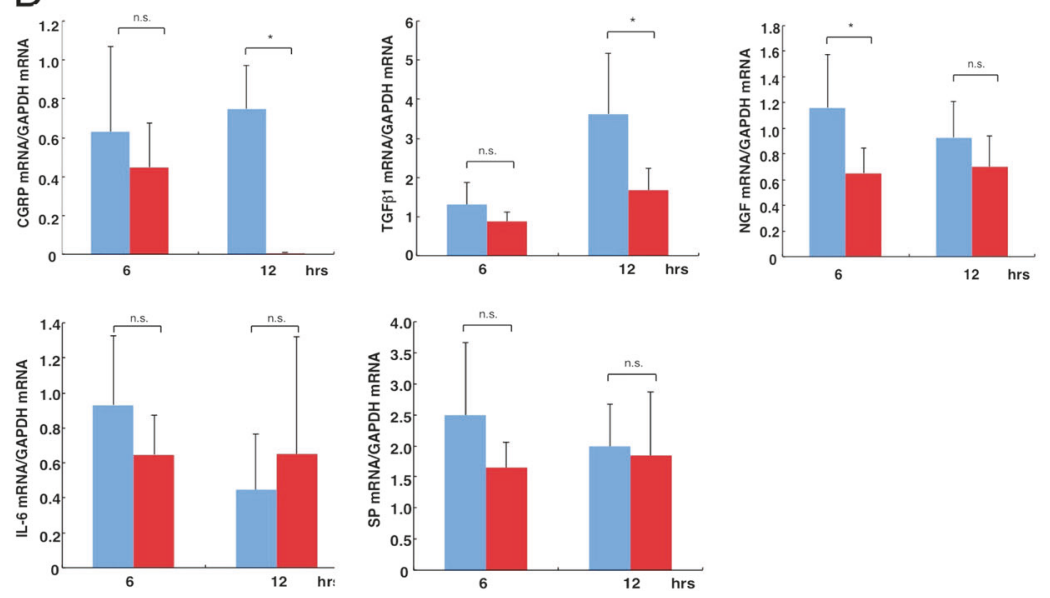

lacking TRPV4 on the expression pattern of epithelial wound healingrelated components was examined by employing real-time RT-PCR. mRNA expression level of calcitonin gene-related peptide (CGRP) and transforming growth factor- $\beta 1$ (TGF $\beta 1$ ) was downregulated by the loss of TRPV4 channel at $12 \mathrm{~h}$ post epithelial wounding. Expression of nerve growth factor (NGF) was downregulated in an uninjured cornea by the loss of TRPV4. mRNA expression of interleukin-6 (IL-6) and substance $\mathrm{P}$ was unaltered by TRPV4 gene ablation. Data represent the mean \pm SEM. $* P<0.05$ by Mann-Whitney $U$ test $(\mathbf{c}, \mathbf{d})$

epithelium with control AAV (Fig. 8b). Immunostaining for TRPV4 was less marked in a KO cornea with TRPV4-AAV as compared to a WT cornea (Fig. 8b). TRPV4 gene transfer to the trigeminal nerve did not upregulate TRPV4 in retina (Supplemental data 2). These results show that the retardation of epithelial healing in a $\mathrm{KO}$ mouse was rescued by TRPV4 gene introduction to the trigeminal nerve (Fig. 8c, d).

\section{Reversal of sensory nerve denervation-induced retardation of epithelial wound healing by TRPV4 gene introduction to the injured trigeminal nerve}

We then hypothesized that in vivo TRPV4 gene transfer might exert an effect similar to that observed in above series 
A
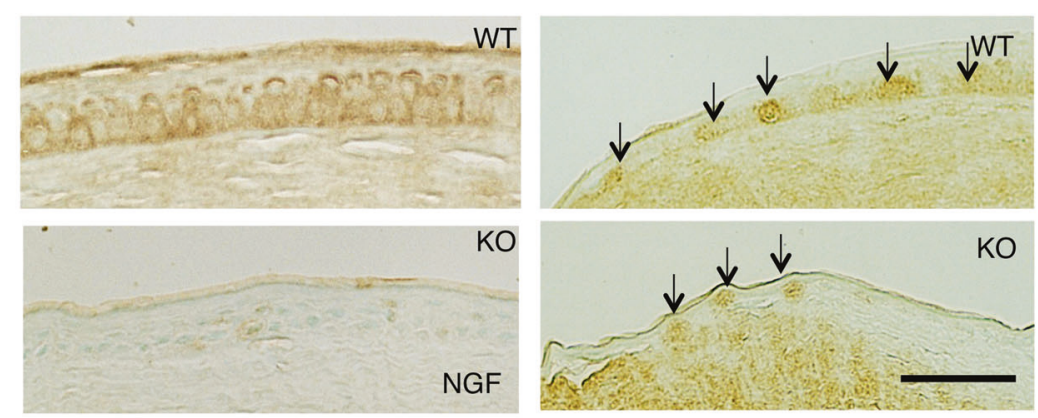

Corneal epithelium

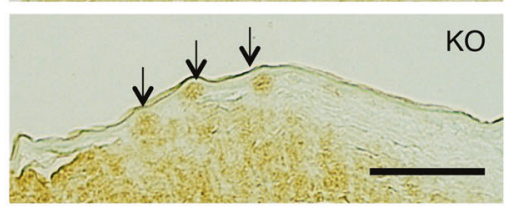

Peripheral/limbus

B
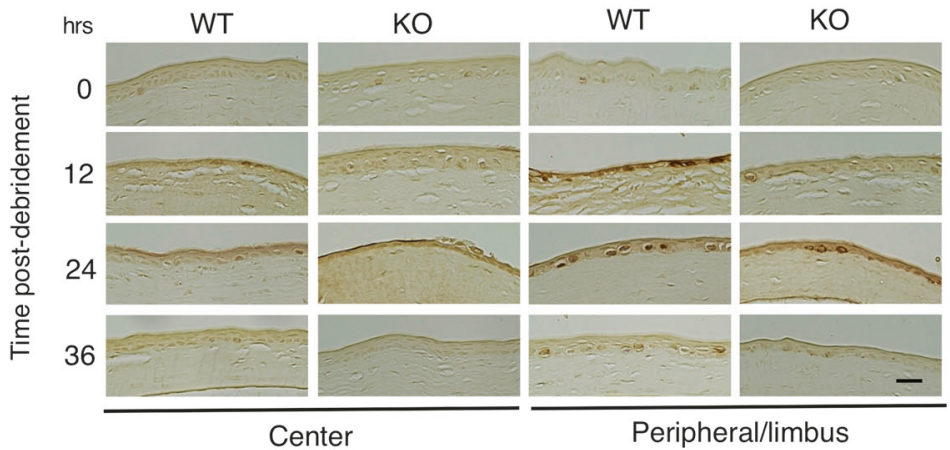

Peripheral/limbus

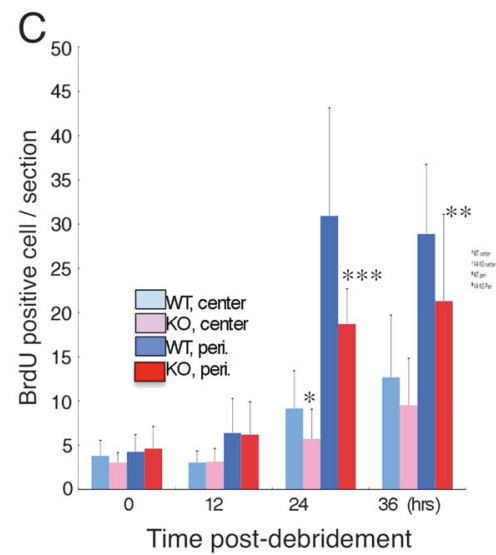

proliferative potential is labeled with diaminobenzidine reaction. Scale bar: $100 \mu \mathrm{m}$. c The number of BrdU-labeled cells in a specific area increased at 24 and $36 \mathrm{~h}$ as compared to 0 or $12 \mathrm{~h}(n=4$ in each genotype at each time point). The increase in labeled cells is counteracted by the loss of TRPV4 at 0 or $12 \mathrm{~h}$ post debridement. Data represent the mean \pm SEM. $* P<0.05, * * P<0.01$ and $* * * P<0.005$ by Mann-Whitney $U$ test (c)

trigeminal TRPV4 gene transfer in the whole cornea. TRPV4 mRNA expression was much higher in the intracranial trigeminal nerve branch in a mouse with TRPV4 gene transfer as compared to the tissue of a mouse with control AAV (Fig. 9d).

At 1 month after AAV gene transfer, healing of a round epithelial wound in the cornea was evaluated. As shown in Fig. 10a, closure of a round epithelial defect in the center of the cornea of mice that had received trigeminal stereotactic electrolysis was recovered by introduction of the TRPV4 gene to the damaged nerve as compared to control AAV treatment. Figure 10b shows the size of remaining epithelial defect at each time point, and after $24 \mathrm{~h}$ post wounding the healing of the defect was markedly promoted by TRPV4 gene transfer as compared to the cornea with nonfunctioning gene. ABCG2 and Hes1 were strongly expressed in the basal cell layer of the peripheral/limbal epithelium of a healthy WT mouse (Fig. 10c). Trigeminal nerve 
A
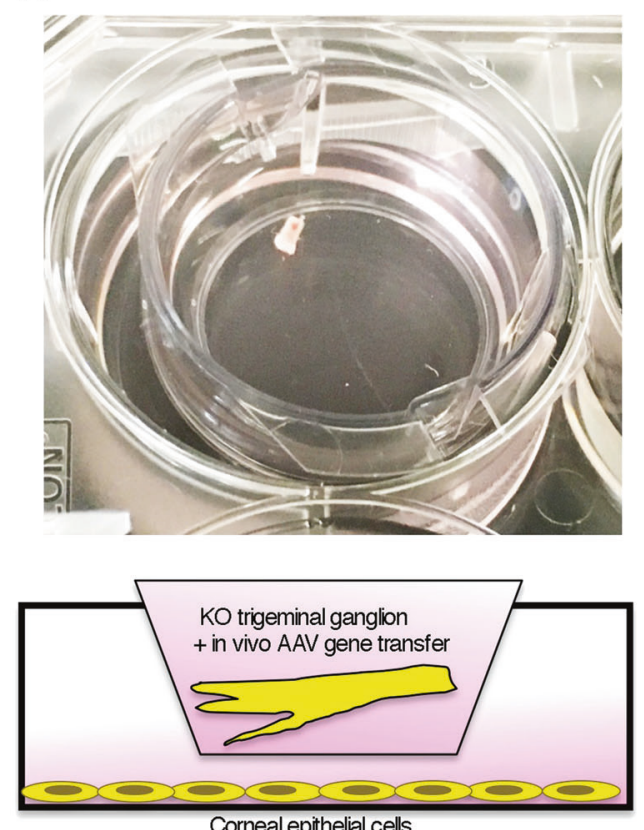

Corneal epithelial cells
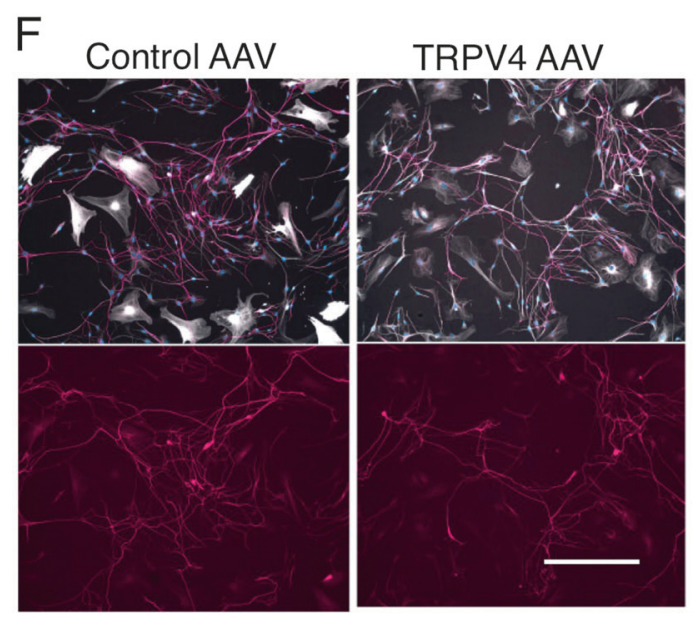

B

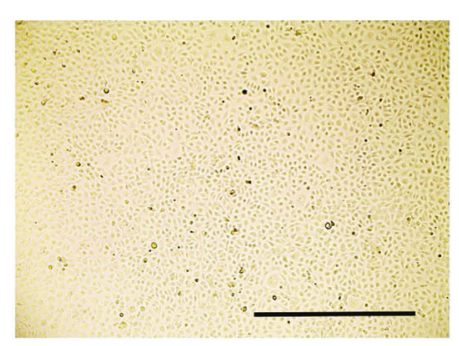

D

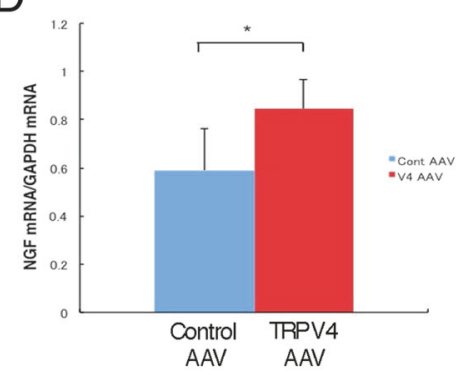

G
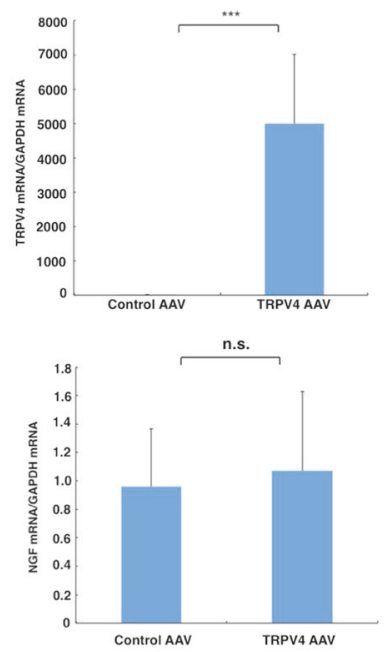

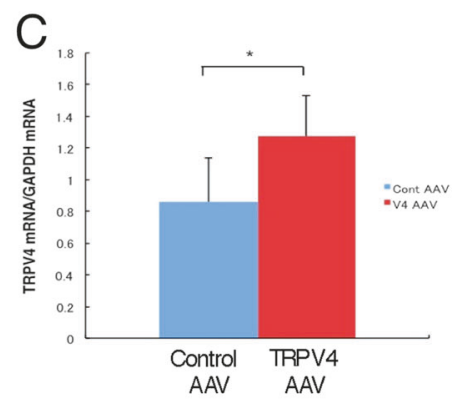

$\mathrm{E}$
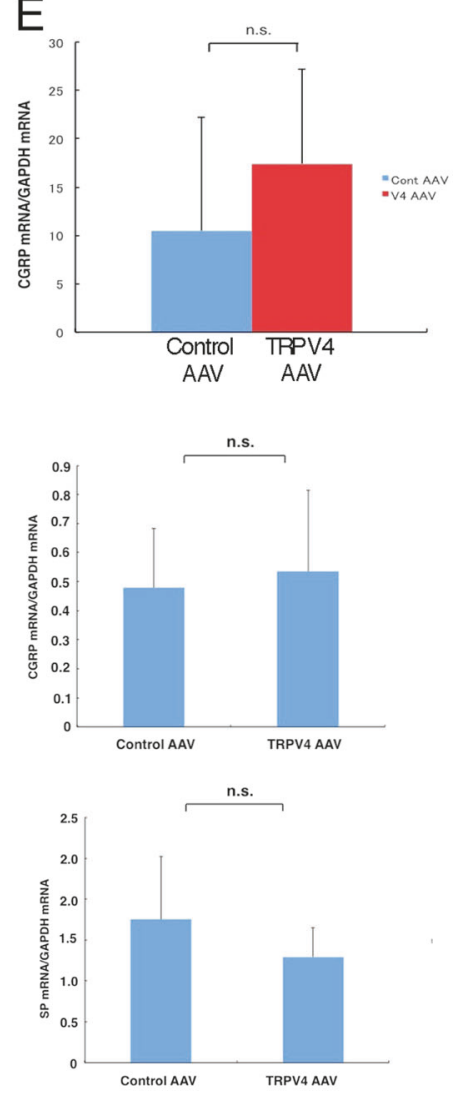

Fig. 7 The effects of TRPV4 gene introduction to the trigeminal nerve on gene expression of corneal epithelial cells or cells derived from trigeminal ganglion. a A double-well co-culture was prepared. TRPV4-null trigeminal ganglion (arrow) using either TRPV4-AAV or control AAV ( $n=6$ in each AAV group) was placed in the upper well. b Mouse corneal epithelial cell line was cultured until reaching confluence in the lower well. Scale bar: $500 \mu \mathrm{m}$. c-e mRNA expression of TRPV4 (c) and nerve growth factor (NGF) (d), but not calcitonin gene-related peptide (CGRP) (e), in the cells in the lower well is upregulated when cultured with a trigeminal ganglion that had received TRPV4 gene introduction as compared to the cells cultured in the presence of the control gene-transferred ganglion. $\mathbf{f}$ Trigeminal ganglion from a KO mouse was dispersed, cultured and processed for TRPV4 gene transfer using either an AAV- or control vector for mRNA expression analysis. G. After $24 \mathrm{~h}$, culture of the cells mRNA expression of CGRP, NGF and substance $\mathrm{P}$ in a ganglion-derived culture was unchanged by TRPV4 overexpression. Data represent the mean \pm SEM. $* P<0.05(\mathrm{C}, \quad \mathrm{D})$ and $* * * P<0.005(\mathrm{G})$ by Mann-Whitney $U$ test $(\mathbf{g})$

carried out to determine the pro-NGF spacial expression pattern in the cornea and showed that pro-NGF expression in the corneal epithelium was unaltered by TRPV4-AAV treatment (Fig. 10e). However, protein expression of proNGF in peripheral/limbal epithelium was upregulated by TRPV4 gene transfer as compared with control AAV (Fig. 10e). 
A
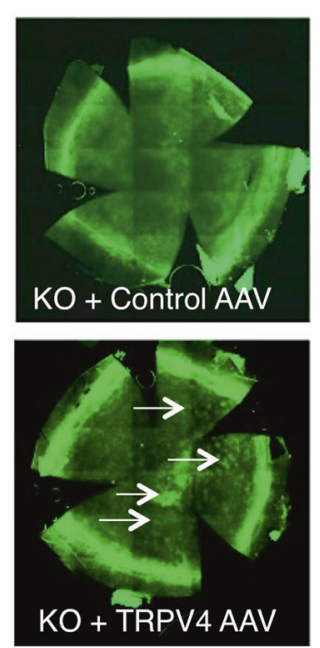

B

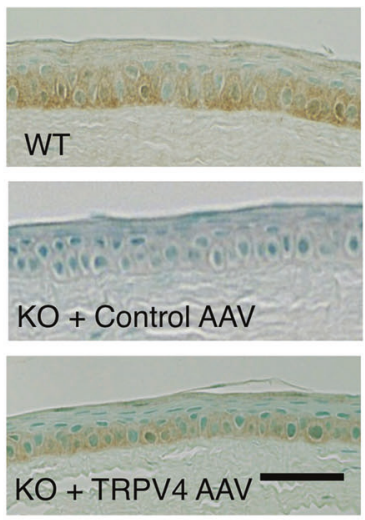

D

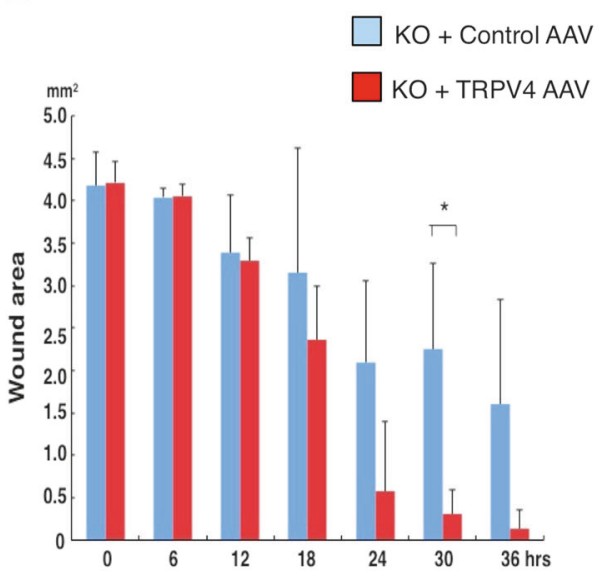

C

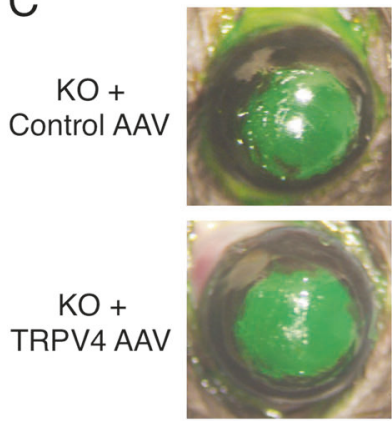

0
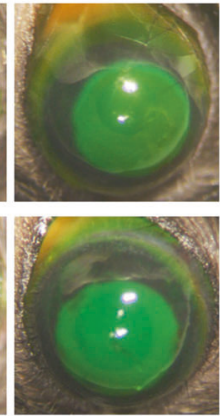

6
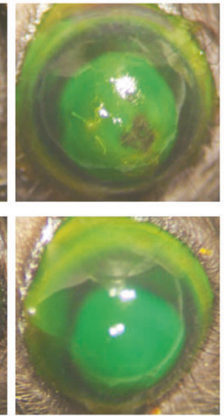

12

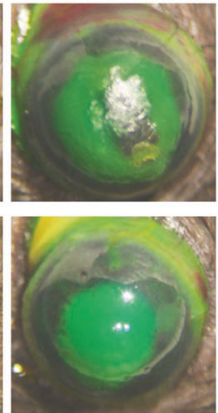

18

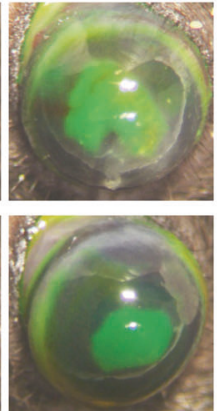

24

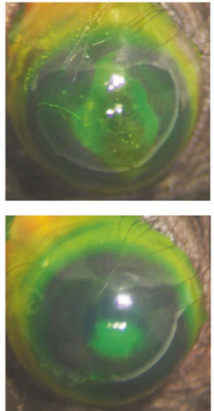

30

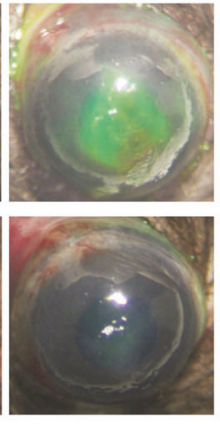

36 hrs

Fig. 8 Gene introduction of TRPV4 to the trigeminal nerve via adenoassociated viral (AAV) vector rescues impairment of corneal epithelial healing in a TRPV4-null (KO) mouse. We examined if AAV gene transfer of TRPV4 to trigeminal ganglion rescues the attenuation of corneal epithelial repair in a $\mathrm{KO}$ mouse. a Immunohistochemistry in whole-mounted specimens showed more marked diffuse expression of TRPV4 (arrows) in a KO cornea with gene transfer as compared to that with control vector. b Immunohistochemistry in paraffin sections indicates that AAV-derived TRPV4 gene transfer upregulates TRPV4

TRPV4 gene introduction to the nerve increased BrdUlabeled cells in the epithelium of peripheral/limbal epithelium and of the central cornea at $12 \mathrm{~h}$ post debridement. At $24 \mathrm{~h}$ post injury, BrdU-positive epithelial cells increased in the central cornea in both groups of control AAV and TRPV4-AAV, although there was no difference in the appearance of BrdU-labeled cells between the two groups. At this time point cell proliferation was also upregulated in peripheral/limbal epithelial cells in the TRPV4-AAV group, while the peripheral/limbal cells in the control AAV-treated cornea failed to show an increase in BrdU-incorporated epithelial cells (Fig. 10f, g). in basal layer of a $\mathrm{KO}$ corneal epithelium, while TRPV4 protein is not detected in a KO cornea with control vector. TRPV4 expression in a $\mathrm{KO}$ cornea with gene transfer is less marked as compared to a wildtype (WT) epithelium. Scale bar: $100 \mu \mathrm{m}$. c, d The defect closure in epithelium was evaluated with green fluorescein staining at each time point. The retardation of epithelial healing in a $\mathrm{KO}$ mouse was rescued by TRPV4 gene introduction to the trigeminal ganglion with statistical significance at $30 \mathrm{~h}$. Data represent the mean \pm SEM. $* P<0.05$ by Mann-Whitney $U$ test (d)

\section{Discussion}

In the present study we modified a protocol reported by Ferrari et al. [37] by employing a thinner coagulation needle and successfully developed a new neurotrophic keratopathy mouse model. Our model yielded a normal-looking corneal surface without inflammatory cell infiltration when uninjured, but exhibited delayed epithelial repair upon debridement. A similar finding was previously reported using a rat neurotrophic keratopathy model [55], suggesting the degree of the coagulation of $\mathrm{V} 1$ nerve correlates with the phenotype of the impairment of tissue homeostasis. In our current model nerve fiber density in the peripheral/limbal 

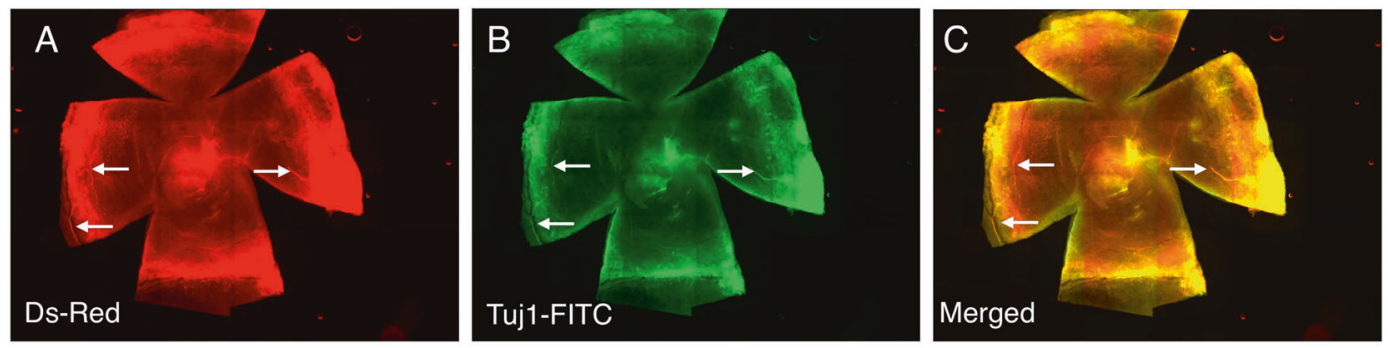

D
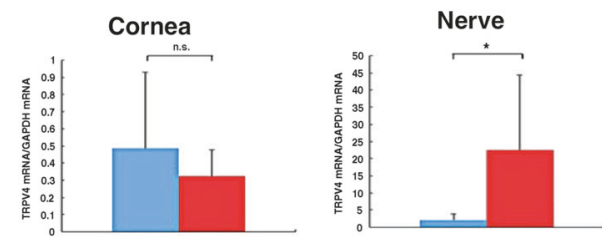

Fig. 9 Adeno-associated viral (AAV) vector gene transfer to the intracranial coagulated first branch of the trigeminal nerve. a-c Mice 1 month following the denervation treatment received stereotactic application of either control or TRPV4-carrying DsRed-labeled AAV to the first branch of the trigeminal nerve. At 1 month after gene transfer the cornea was processed for whole-mounted immunohistochemistry for Tuj1 with green fluorescein. Central and midperipheral cornea is free from sensory nerve fibers. The fibers sparsely located to the very peripheral cornea were labeled for both DsRed (AAV vector) (a, arrows) and green fluorescein (Tuj1) (b, arrows). c

area was much less in the eye with V1 nerve coagulation as compared with a control eye. This finding clearly indicates that sensory nerve function is critical to the homeostasis of the tissue, i.e., wound healing response, in the corneal epithelium. In this model, attenuation of healing of an epithelial defect was mainly observed in the later phase. A similar finding was reported in cutaneous wound healing; sensory innervation reportedly plays a critical role in modulating behavior of keratinocytes and presumably other cellular components during wound healing [56].

Gene expression analysis was performed to clarify the mechanism underlying delayed epithelial healing of corneal epithelial cells associated with sensory denervation. Interactions between immune cells and the sensory nerve in cornea have been previously reported [57]. Severe trigeminal denervation spontaneously induces local inflammation in cornea [37]. In the current mouse model, the 20-guage needle causes less severe nerve coagulation, but expression of TRPV1 and NGF mRNAs was significantly upregulated in the uninjured corneal samples, consistent with the previously published model [24]. However, the current treatment did not induce spontaneous inflammation, an improvement over the treatment method with an 18-guage needle, although both TRPV1 and NGF could potentially accelerate local inflammation [39, 58]. Similar findings were reported in skin; expression of NGF in epidermis was enhanced following chronic constriction injury of the sciatic
Merged picture from $(\mathbf{b}, \mathbf{c})$. The finding indicated that the AAV vectors moved down in to the peripheral residual nerve fibers (arrows). TRPV4 gene introduction did not stimulate regeneration of sensory nerve fibers in central cornea. d mRNA expression analysis was conducted in specimens $12 \mathrm{~h}$ after epithelial debridement. mRNA expression level of TRPV4 in cornea was not affected by gene transfer to the nerve, while it is much higher in the intracranial trigeminal nerve branch in a mouse with TRPV4 gene transfer as compared to the tissue of a mouse with control AAV $(n=5)$. Data represent the mean \pm SEM. $* P<0.05$ by Mann-Whitney $U$ test $(\mathbf{d})$

nerve, presumably due to the effects from nerve-derived neurotransmitters $[59,60]$. In the present study, expression of TRPA1, TRPV4 and NGF was upregulated in response to epithelial debridement in a cornea of a control animal without V1 nerve coagulation, and was counteracted by nerve electrolysis. Suppression of upregulation of NGF might attenuate proliferation potential of epithelial cells that may be one of the mechanisms underlying impairment of epithelial healing by denervation [7, 61, 62]. Therefore, we performed immunohistochemistry for markers of stem/progenitor cells (ABCG2 and Hes1), pro-NGF and BrdU. Expression of ABCG2 and Hes1 in the basal cells of the peripheral/limbal epithelium was dramatically suppressed by the current protocol and it was recovered by TRPV4 gene introduction into the damaged nerve. Corneal epithelium expressed pro-NGF with or without trigeminal denervation. However, at 12 and $24 \mathrm{~h}$ post epithelial debridement, its expression was less intense in the peripheral/ limbal epithelium of a cornea of the denervated mouse as compared to a healthy control. Trigeminal denervation suppresses cell proliferation of healing peripheral/limbal epithelium as early as $12 \mathrm{~h}$ post injury in both central and peripheral epithelia at $24 \mathrm{~h}$. Cell proliferation inhibition was more prominent in the peripheral/limbal epithelium and it coincides with the finding in the previous reports that sensory innervation is critical in maintenance of stem cell potential in the limbus [24]. The similar role of the neural 

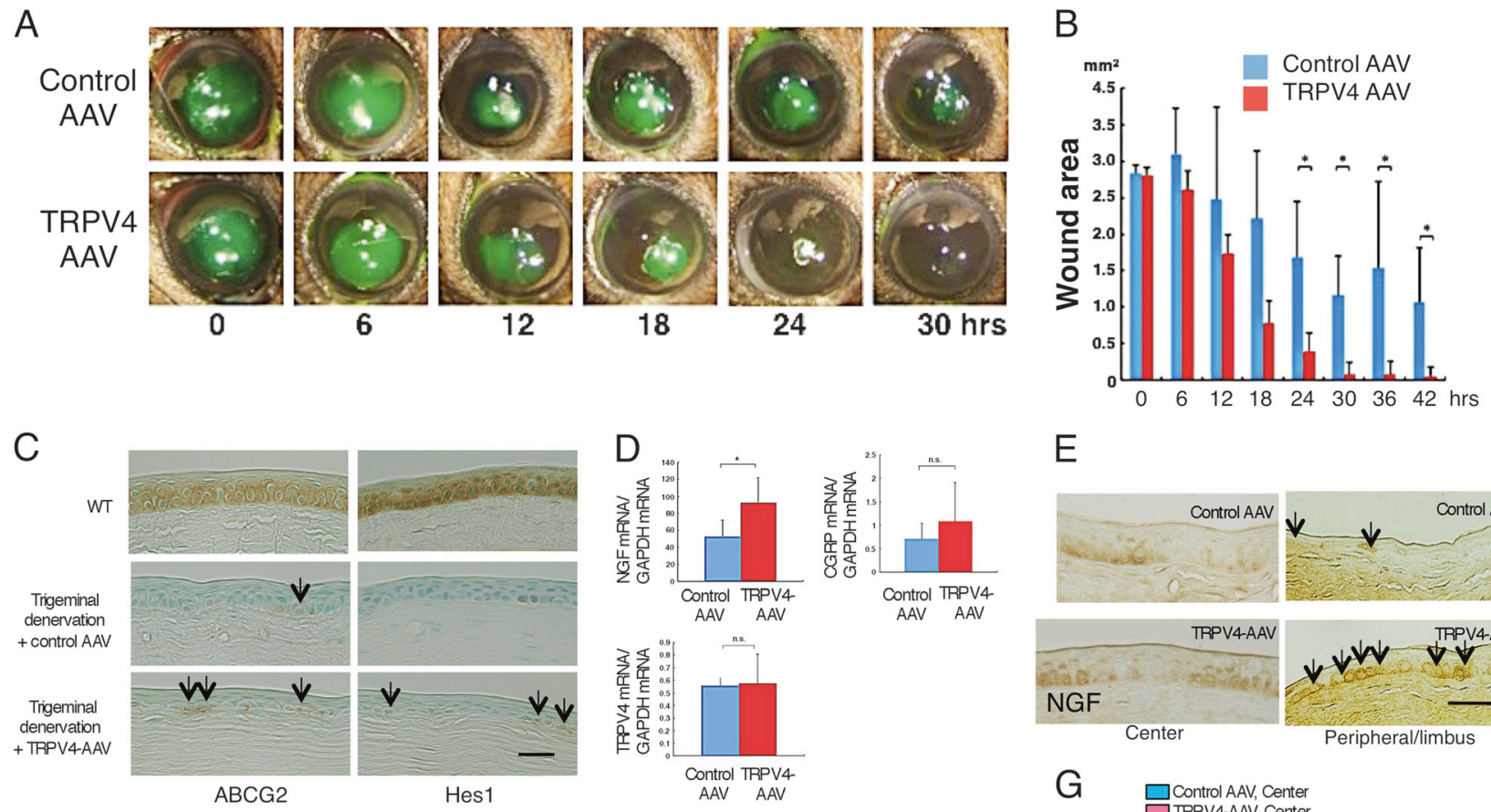

E
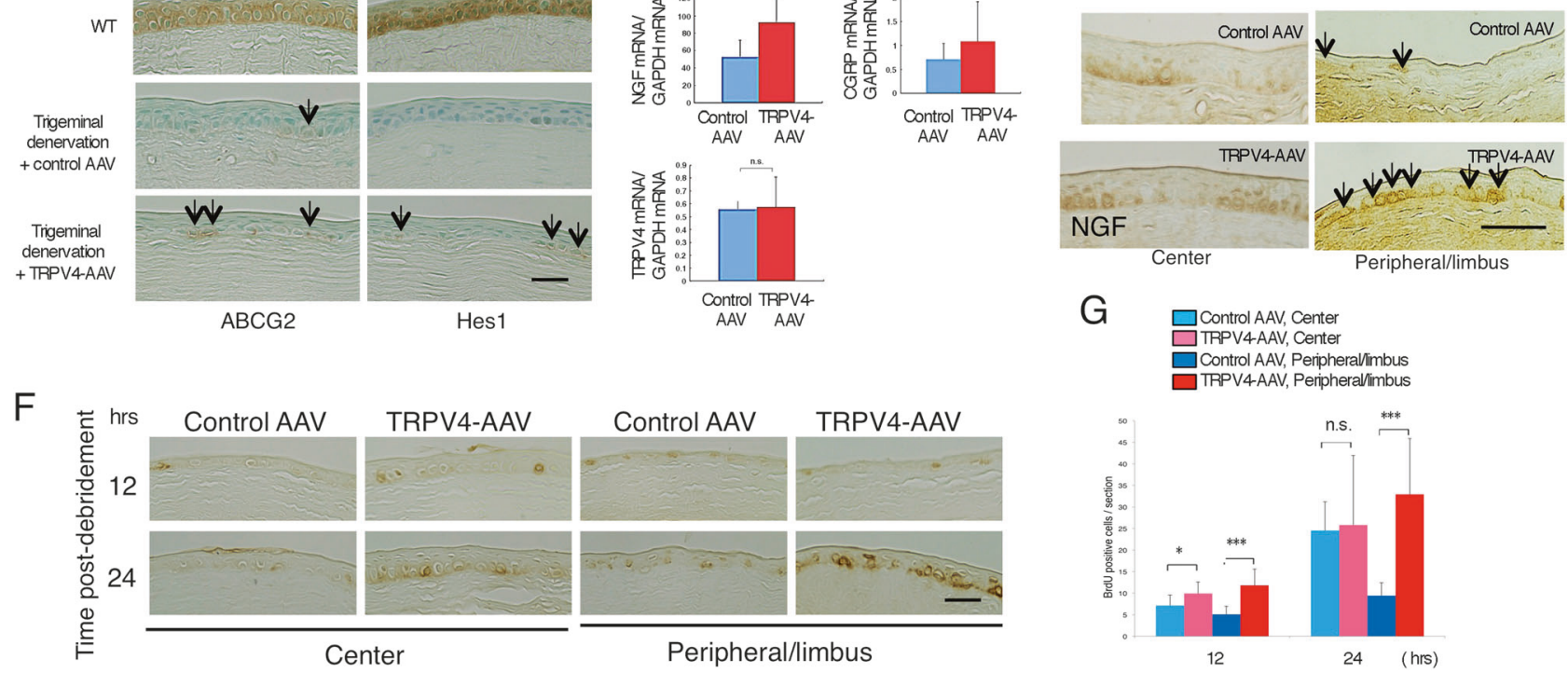

Fig. 10 Reversal of trigeminal coagulation-induced retardation of epithelial wound healing by TRPV4 gene introduction to the injured intracranial nerve. At 1 month after AAV gene transfer, healing of a round epithelial defect in the cornea was evaluated as described above. a TRPV4 gene introduction to the damaged nerve reverses the impairment of the epithelial defect healing as compared to control AAV vector. At $24 \mathrm{~h}$ post debridement, a cornea of the TRPV4-vector group exhibits a minor epithelial defect, while obvious round defect remains with control vector. b The remaining defect is significantly larger in corneas of control AAV group as compared to those of TRPV4-AAV group at 24, 30, 36 and $42 \mathrm{~h}$. $\mathbf{c}$ The healthy epithelium is strongly labeled for limbal stem/progenitor cell markers, ABCG2 and Hes1, while trigeminal coagulation suppresses their expression. TRPV4 gene transfer to the damaged nerve partially recovers expression of ABCG2 and Hes 1 in the basal cells of peripheral/limbal epithelium (arrows). Scale bar: $100 \mu \mathrm{m}$. d At $12 \mathrm{~h}$ post wounding, expression of nerve growth factor (NGF)), but not calcitonin generelated peptide (CGRP) or TRPV4, is upregulated by TRPV4 gene transfer. e Protein expression of NGF in basal cells of the corneal epithelium of a control AAV mouse is similar to that of a mouse with TRPV4 gene transfer. In the limbal region NGF expression in basal epithelial cells (arrows) is upregulated by TRPV4 gene transfer as compared to control AAV treatment. Scale bar: $100 \mu \mathrm{m}$. f Detection of BrdU-labeled cells in central and peripheral/limbal epithelia was performed at 12 and $24 \mathrm{~h}$ post debridement to understand the involvement of cell proliferation in reversal of epithelial healing impairment. f Cell proliferation in healing epithelium was higher in cornea of a mouse with TRPV4 gene transfer as compared to a control AAV mouse. Scale bar: $100 \mu \mathrm{m}$. g The results of counting BrdU-labeled cells in central and peripheral/limbal epithelia at 12 and $24 \mathrm{~h}$. Data represent the mean \pm SEM. $* P<0.05$ and $* * * P<0.005$ by Mann-Whitney $U$ test $(\mathbf{b}, \mathbf{d}, \mathbf{g})$ components in the maintenance of stemness in tissue was reported in bone marrow, tooth and hair follicle, consistent with the current finding [63-65].

In the cornea of a mouse after trigeminal denervation, counteraction to upregulation of TRPV4 mRNA expression by the denervation treatment was most prominent among the components examined. We therefore focused on the roles of TRPV4 cation channel in modulation of epithelial healing in a mouse cornea in the current project, although a variety of components could be involved. Expression of substance $\mathrm{P}$ and TGF $\beta 1$ was unchanged by the nerve coagulation and also by the epithelial debridement, although both components are also reportedly involved in epithelial repair in cornea $[66,67]$. We examined the effect of blockage or global loss of TRPV4 function on epithelial wound healing in vivo and in vitro, respectively. Blocking of TRPV4 receptor signal did not affect cell movement in cultured TKE2 corneal epithelial cell monolayer, suggesting 
TRPV4 does not play an important role in modulation of migration of corneal epithelial cells in a condition free from other cell types. Similarly, spreading of an epithelial sheet on corneal stroma cut surface was not affected in an organ culture. These findings indicate that migration of each single corneal epithelial cell was minimally modulated by TRPV4 signal. In vivo epithelial healing in cornea is a complex process that could be influenced by proliferating cell providing by limbal stem cells and by cell migration modulation via components of underlying basement membrane. Thus, before we perform an in vivo assay of the roles of TRPV4 in corneal epithelial healing, we conducted an organ culture experiment using a whole eyeball. This wound healing model excluded the involvement of bone marrow-derived inflammatory cells in modulation of behaviors of corneal epithelial cells. However, it was not excluded that the nerves in the enucleated eye might not survive during the early phase of culture. At $36 \mathrm{~h}$ of culture, sensory nerve fibers were observed in the corneal stroma, although the fibers seemed to be of a somewhat beaded configuration that could suggest the process of Wallerian degeneration. Nevertheless, a possibility that mediators expressed in the nerve fibers in the tissue might affect the behaviors of the epithelial cells during epithelium healing in situ could not be excluded.

We then showed global gene ablation of TRPV4 retarded healing of an epithelial defect in a mouse cornea; statistically significant delay of the resurfacing of the epithelial defect was detected at $18 \mathrm{~h}$ and $24 \mathrm{~h}$ post epithelial debridement, but not during the earlier phase of healing, i.e., until $12 \mathrm{~h}$. Impact of TRPV4 gene ablation was more prominent in the peripheral (including limbus) epithelium than in central epithelium; the number of BrdU-labeled cells in healing epithelium was similar between WT and KO mice at time points of 0 and $12 \mathrm{~h}$ post wounding. At 24 and $36 \mathrm{~h}$, cell proliferation increased in central and, more markedly, in peripheral/limbal epithelium. Such promotion of cell proliferation was counteracted by the loss of TRPV4. This indicates that lacking TRPV4 attenuates epithelial healing mainly by suppression of cell proliferation in peripheral/ limbal epithelium that contains limbal stem cells similar to our neurotrophic keratopathy model. Real-time RT-PCR showed that expression of CGRP, TGF $\beta 1$ and NGF was suppressed in the $\mathrm{KO}$ whole corneas as compared to WT tissues at either 6 or $12 \mathrm{~h}$ post epithelial debridement.

NGF and CGRP are both reportedly involved in acceleration of cell proliferation and wound healing in epidermis or corneal epithelium [60, 61, 68, 69]. As described above, expression of CGRP was not affected by trigeminal denervation. CGRP is expressed by both local tissue (epithelium) and sensory nerve and is capable of modulation of cell proliferation [70]. In our model CGRP upregulation during corneal epithelial healing was not counteracted by sensory denervation dissimilar to the finding in a $\mathrm{KO}$ mouse; there was a possibility that upregulation of CGRP in the epithelium by injury might mask the loss of sensory CGRP in cornea.

Protein expression of pro-NGF was suppressed by TRPV4 gene knockout in both corneal and limbal epithelium. It was reported that limbal epithelial stem cells, positive for $\mathrm{p} 75$ and TrkA NGF receptors, are critical in providing epithelial cells with proliferative potential to the corneal center for recovery as the stem cell lineage [71]. Downregulation of expression of (pro-)NGF in corneal and limbal epithelia might negatively impact the proliferation of limbal stem cells of a KO mouse. This finding supports the previous data that NGF accelerates epithelial healing in cornea [6-9].

To know the effects of TRPV4 gene transfer in trigeminal ganglion on gene expression in corneal epithelial cells, we conducted a co-culture experiment. In this co-culture the ganglion and TKE2 corneal epithelial cells shared the culture medium but were cultured separately without physical contact. It was reported that proliferation of rabbit corneal epithelial cells was promoted by co-culturing with sensory neurons from the trigeminal ganglia [72, 73]. Our current results show that $\mathrm{KO}$ trigeminal ganglion that had received in vivo TRPV4 gene transfer upregulated NGF and TRPV4 (no significant value in increment of CGRP expression level) in cultured corneal epithelial cells as compared with a control AAV-treated KO ganglion. Unknown factor(s) secreted by TRPV4 gene-transferred trigeminal ganglion was (were) considered to affect corneal epithelial cell layer and lead to NGF upregulation. TRPV4 gene transfer did not upregulate NGF, substance $\mathrm{P}$ and CGRP in cells in the ganglion.

As described above, expression of TRPV4 mRNA in cornea was markedly suppressed in a healing epithelium by the trigeminal denervation, and the global knockout of TRPV4 gene indeed retarded corneal epithelial healing. Protein expression of pro-NGF seemed to be suppressed in peripheral/limbal epithelium and cell proliferation suppression was more prominent in the same area as compared to central epithelium in the sensory denervated cornea. Similarly, cell proliferation suppression was more marked in peripheral/limbal epithelium and cell proliferation suppression was also more prominent in the same area as compared to central epithelium in a KO mouse. Because TRPV4 overexpression in trigeminal ganglion upregulates NGF expression in co-cultured epithelial cells (but not in the nerve ganglion cells), we hypothesized that TRPV4 gene introduction to the damaged trigeminal nerve rescues the impairment of corneal epithelium wound healing via NGF upregulation in the local epithelium. To explore the hypothesis we employed an in vivo gene transfer system of an AAV vector carrying mouse TRPV4 gene. Because our 
Fig. 11 Proposal model of the mechanism of how sensory nerve TRPV4 rescues impairment of epithelial healing in sensory denervated cornea. Overexprressed TRPV4 in remaining sensory nerve stimulates basal cells in the peripheral/limbal epithelium to restore stemness and to express nerve growth factor (NGF). TRPV4 gene transfer does not accelerate regeneration of the sensory nerve fibers. NGF enhances cell proliferation in the peripheral/limbal epithelium that promotes wound healing in a defected epithelium

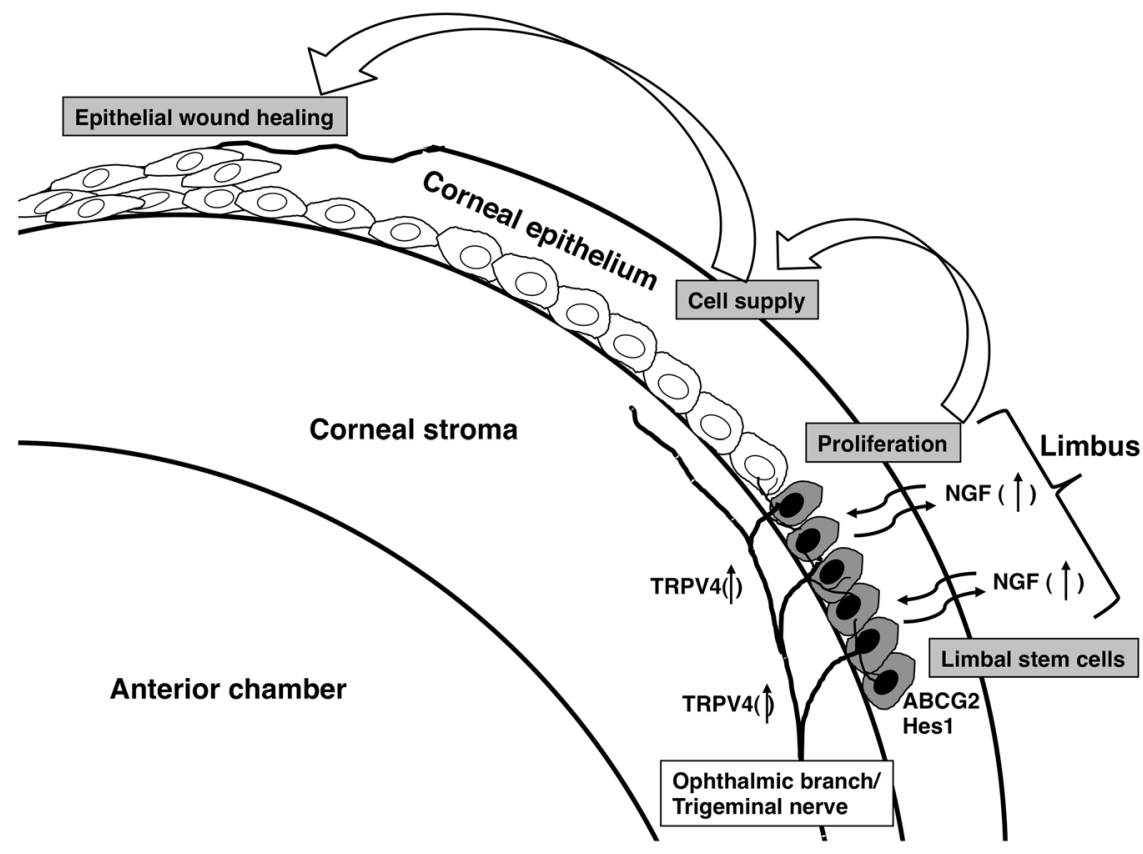

preliminary experiment showed that AAV that carries green fluorescent protein (GFP) to a healthy first branch of the trigeminal nerve and saw GFP came down into the nerve fibers in the peripheral corneal epithelium (data not shown). We thus infected the vector carrying both TRPV4 gene and DsRed to partially damaged trigeminal nerve first branch, and examined its effect on epithelial debridement healing. DsRed was detected in the remaining surviving TuJ1labeled nerve fibers in the peripheral/limbal area that indicates the exogenous gene was expressed in the peripheral limbal sensory nerve fibers that survived after the electrolysis treatment. TRPV4 gene introduction did not stimulate regeneration of sensory nerve fibers in central cornea in the present study, but the surviving fibers were only seen in the peripheral limbal region. Real-time RT-PCR showed elevated TRPV4 mRNA expression in the first branch of the nerve, but not in cornea, presumably because TRPV4 expressed in the epithelium and/or keratocytes might mask the expression in the gene-introduced nerve fibers in peripheral remaining cornea. Nevertheless, TRPV4 gene transfer to the injured intracranial nerve reversed the delayed healing in a corneal epithelium defect in the later phase of healing. Because later phase healing of an epithelial debridement mainly depends on cell proliferation rather than cell migration, we expected the recovery of the impaired healing by TRPV4 gene introduction to the nerve might depend on upregulation of NGF and cell proliferation promotion in the limbal epithelium. This hypothesis was well cleared by the results as follows; mRNA expression of NGF was upregulated in a sample of the whole cornea with healing epithelium of denervated cornea at $12 \mathrm{~h}$ in the mouse with TRPV4 gene transfer. Moreover, immunohistochemistry demonstrated that pro-NGF expression was more marked in the TRPV4-AAV-treated peripheral/limbal epithelium as compared to a control AAV cornea. Such difference was less marked in the central epithelium between the two groups. Finally, TRPV4 gene transfer to the survived nerve fibers upregulated cell proliferation in peripheral/limbal epithelial cells, the main provider of cell renewal in cornea. Overexpression of TRPV4 in remaining nerve fibers in peripheral/limbal region might activate the peripheral/limbal epithelium to upregulate (pro-)NGF via (an) unknown factor(s) from TRPV4-positive sensory nerve fibers. Although NGF is reportedly involved in re-growth of corneal sensory nerve fibers $[74,75]$, sensory nerve fiber loss in the central cornea was not recovered by TRPV4 overexpression. TRPV4 in the remaining sensory nerves in the peripheral/limbal zone played an important role in the recovery of stemness of the basal epithelial cells.

The exact reason why the gene transfer of only TRPV4 exerted a recovery potential in attenuated epithelial healing although sensory denervation suppressed expression of both TRPV4 and TRPA1 in cornea remains to be examined. However, explanations might include that overexpressed TRPV4 could compensate the reduced expression of TRPA1 in remaining nerves in cornea. The notion could be supported by a report that both TRPV4 and TRPA1 cooperate the pain sensation in pancreas [76]. Our unpublished data could support this theory; gene ablation of TRPA1 attenuated epithelial healing in cornea and the impairment of epithelial healing in the denervated cornea produced by the same procedure with a 20 -guage needle was well 
rescued by AAV gene transfer of TRPA1 to the intracranial trigeminal nerve.

In summary (Fig. 11), sensory denervation-induced impairment of corneal epithelial wound healing was associated with downregulation of TRPV4 (and TRPA1) and NGF in the local tissue. Global knockout of TRPV4 also retarded corneal epithelial healing and downregulated expression of NGF that was recovered with TRPV4 gene transfer to the intact trigeminal nerve. The attenuation of epithelial wound healing was mainly caused by the suppression of cell proliferation in peripheral/limbal epithelial cells, presumably stem-like cells. Then, attenuation of corneal epithelial healing by sensory nerve damage was rescued by TRPV4 gene transfer to the nerve with recovery of proliferation in peripheral/limbal epithelial stem cells and of local NGF expression, although the damaged nerve was not regenerated by the procedure. Sensory nerve TRPV4 is critical to maintain stemness of peripheral/limbal basal cell, and this is one of the major mechanisms of homeostasis of corneal epithelium.

Acknowledgements The authors thank Dr. Kazuhiro Ikeura, Department of Dentistry and Oral Surgery, Keio University School of Medicine, Tokyo, Japan, and Dr. Tetsuya Kawakita, Department of Ophthalmology, Kitasato University Kitasato Institute Hospital, Japan, for providing TKE2 mouse corneal epithelial cell line. The authors also thank Honorary Professor Emiko Senba, Department of Anatomy, Wakayama Medical University, Japan, for instructing stereotactic neuro-electrolysis technique and mouse brain dissection procedure. This study was supported by the Grants from the Ministry of Education, Science, Sports and Culture of Japan (C21592241 to YO, C40433362 to TS, C19592036 to SS), NEI Eye Research Grant EY021510 (to JVJ), NIH/NEI EY011845 \& Ohio Lions Eye Research Foundation (to WW-YK) and NIH ROI EY23086 (to C-YL). The abstract of this work was presented by Dr. Okada in the ARVO Annual Meeting 2016.

\section{Compliance with ethical standards}

Conflict of interest The authors declare that they have no conflict of interest.

\section{References}

1. Liu CY, Kao WW. Corneal epithelial wound healing. Prog Mol Biol Transl Sci. 2015;134:61-71.

2. Ljubimov AV, Saghizadeh M. Progress in corneal wound healing. Prog Retin Eye Res. 2015;49:17-45.

3. Saghizadeh M, Kramerov AA, Svendsen CN, et al. Concise review: stem cells for corneal wound healing. Stem Cells. 2017;35:2105-14.

4. Yazdanpanah G, Jabbehdari S, Djalilian AR. Limbal and corneal epithelial homeostasis. Curr Opin Ophthalmol. 2017;28:348-54.

5. Castro-Muñozledo F. Review: corneal epithelial stem cells, their niche and wound healing. Mol Vis. 2013;19:1600-13.

6. Di Girolamo N, Sarris M, Chi J, et al. Localization of the lowaffinity nerve growth factor receptor p75 in human limbal epithelial cells. J Cell Mol Med. 2008;12:2799-811.
7. Qi H, Li DQ, Shine HD, et al. Nerve growth factor and its receptor TrkA serve as potential markers for human corneal epithelial progenitor cells. Exp Eye Res. 2008;86:34-40.

8. Lambiase A, Manni L, Bonini S, et al. Nerve growth factor promotes corneal healing: structural, biochemical, and molecular analyses of rat and human corneas. Invest Ophthalmol Vis Sci. 2000;41:1063-9.

9. Lambiase A, Aloe L, Mantelli F, et al. Capsaicin-induced corneal sensory denervation and healing impairment are reversed by NGF treatment. Invest Ophthalmol Vis Sci. 2012;53:8280-7.

10. Marfurt CF, Cox J, Deek S, et al. Anatomy of the human corneal innervation. Exp Eye Res. 2010;90:478-92.

11. Müller LJ, Vrensen GF, Pels L, et al. Architecture of human corneal nerves. Invest Ophthalmol Vis Sci. 1997;38:985-94.

12. Shaheen BS, Bakir M, Jain S. Corneal nerves in health and disease. Surv Ophthalmol. 2014;59:263-85.

13. Al-Aqaba MA, Fares U, Suleman H, et al. Architecture and distribution of human corneal nerves. $\mathrm{Br} \mathrm{J}$ Ophthalmol. 2010;94:784-9.

14. Müller LJ, Marfurt CF, Kruse F, et al. Corneal nerves: structure, contents and function. Exp Eye Res. 2003;76:521-42.

15. O'Mullane LM, Keast JR, Osborne PB. Co-cultures provide a new tool to probe communication between adult sensory neurons and urothelium. J Urol. 2013;190:737-45.

16. Bukowiecki A, Hos D, Cursiefen C, et al. Wound-healing studies in cornea and skin: parallels, differences and opportunities. Int $\mathrm{J}$ Mol Sci. 2017;18:pii: E1257.

17. Shi X, Wang L, Clark JD, et al. Keratinocytes express cytokines and nerve growth factor in response to neuropeptide activation of the ERK1/2 and JNK MAPK transcription pathways. Regul Pept. 2013;186:92-103.

18. Roggenkamp D, Köpnick S, Stäb F, et al. Epidermal nerve fibers modulate keratinocyte growth via neuropeptide signaling in an innervated skin model. J Invest Dermatol. 2013;133:1620-8.

19. Ostrowski SM, Belkadi A, Loyd CM, et al. Cutaneous denervation of psoriasiform mouse skin improves acanthosis and inflammation in a sensory neuropeptide-dependent manner. J Invest Dermatol. 2011;131:1530-8.

20. Sivilia S, Paradisi M, D'Intino G, et al. Skin homeostasis during inflammation: a role for nerve growth factor. Histol Histopathol. 2008;23:1-10.

21. Okada Y, Reinach P, Kitano A, et al. Neurotrophic keratopathy; its pathophysiology and treatment. Histol Histopathol. 2010;25:771-80.

22. Sacchetti M, Lambiase A. Diagnosis and management of neurotrophic keratitis. Clin Ophthalmol. 2014;8:571-9.

23. Bonini S, Rama P, Olzi D, et al. Neurotrophic keratitis. Eye (Lond). 2003;17:989-95.

24. Ueno H, Ferrari G, Hattori T, et al. Dependence of corneal stem/ progenitor cells on ocular surface innervation. Invest Ophthalmol Vis Sci. 2012;53:867-72.

25. Lockwood A, Hope-Ross M, Chell P. Neurotrophic keratopathy and diabetes mellitus. Eye (Lond). 2006;20:837-9.

26. Wang F, Gao N, Yin J, et al. Reduced innervation and delayed reinnervation after epithelial wounding in type 2 diabetic GotoKakizaki rats. Am J Pathol. 2012;181:2058-66.

27. He J, Bazan HE. Mapping the nerve architecture of diabetic human corneas. J Ophthalmol. 2012;119:956-64.

28. Hossain P, Sachdev A, Malik RA. Early detection of diabetic peripheral neuropathy with corneal confocal microscopy. Lancet. 2005;366:1340-3.

29. Kaufman SC. Anterior segment complications of herpes zoster ophthalmicus. Ophthalmology. 2008;115 Suppl 2 :S24-32.

30. Abdelkader H, Patel DV, McGhee $\mathrm{CNj}$, et al. New therapeutic approaches in the treatment of diabetic keratopathy: a review. Clin Exp Ophthalmol. 2011;39:259-70. 
31. Reynolds SA, Kabat AG. Therapeutic options for the management of early neurotrophic keratopathy: a case report and review. Optometry. 2006;77:503-7.

32. Lambiase A, Rama P, Aloe L, et al. Management of neurotrophic keratopathy. Curr Opin Ophthalmol. 1999;10:270-6.

33. Sosne G, Rimmer D, Kleinman HK, et al. Thymosin beta 4: a potential novel therapy for neurotrophic keratopathy, dry eye, and ocular surface diseases. Vitam Horm. 2016;102:277-306.

34. Nishida T, Yanai R. Advances in treatment for neurotrophic keratopathy. Curr Opin Ophthalmol. 2009;20:276-81.

35. Suvas $S$. Role of substance $P$ neuropeptide in inflammation, wound healing, and tissue homeostasis. J Immunol. 2017;199:1543-52.

36. Okada Y, Reinach $\mathrm{P}$, Shirai $\mathrm{K}$, et al. TRPV1 involvement in inflammatory tissue fibrosis in mice. Am J Pathol. 2011;178:2654-64.

37. Ferrari G, Chauhan SK, Ueno H, et al. A novel mouse model for neurotrophic keratopathy: trigeminal nerve stereotactic electrolysis through the brain. Invest Ophthalmol Vis Sci. 2011;52:2532-9.

38. Okada Y, Shirai K, Reinach P, et al. TRPA1 is required for TGF- $\beta$ signaling and its loss blocks inflammatory fibrosis in mouse corneal stroma. Lab Invest. 2014;94:1030-41.

39. Okada Y, Shirai K, Miyajima M, et al. Loss of TRPV4 function suppresses inflammatory fibrosis induced by alkali-burning mouse corneas. PLoS One. 2016;11:e0167200.

40. Sumioka T, Okada Y, Reinach PS, et al. Impairment of corneal epithelial wound healing in a TRPV1-deficient mouse. Invest Ophthalmol Vis Sci. 2014;55:3295-302.

41. Meng Q, Fang P, Hu Z, et al. Mechanotransduction of trigeminal ganglion neurons innervating inner walls of rat anterior eye chambers. Am J Physiol Cell Physiol. 2015;309:C1-10.

42. Vandewauw I, Owsianik G, Voets T. Systematic and quantitative mRNA expression analysis of TRP channel genes at the single trigeminal and dorsal root ganglion level in mouse. BMC Neurosci. 2013;14:21

43. Bakri MM, Yahya F, Munawar KMM, et al. Transient receptor potential vanilloid 4 (TRPV4) expression on the nerve fibers of human dental pulp is upregulated under inflammatory condition. Arch Oral Biol. 2018;89:94-8.

44. Okada Y, Saika S, Shirai K. et al. AP-1(c-fos/c-Jun) is required for corneal epithelial spreading. Graefes Arch Clin Exp Ophthalmol. 2003;241:327-9.

45. Saika S, Kono-Saika S, Tanaka T, et al. Smad3 is required for dedifferentiation of retinal pigment epithelium following retinal detachment in mice. Lab Invest. 2004;84:1245-58.

46. Nishida $\mathrm{T}$, Nakagawa $\mathrm{S}$, Awata $\mathrm{T}$, et al. Fibronectin promotes epithelial migration of cultured rabbit cornea in situ. J Cell Biol. 1983;97:1653-7.

47. Mizuno A, Matsumoto N, Imai M, et al. Impaired osmotic sensation in mice lacking TRPV4. Am J Physiol Cell Physiol. 2003;285:C96-101.

48. Suzuki M, Mizuno A, Kodaira K, et al. Impaired pressure sensation in mice lacking TRPV4. J Biol Chem. 2003;278:22664-8.

49. Kobayashi K, Sano H, Kato S, et al. Survival of corticostriatal neurons by Rho/Rho-kinase signaling pathway. Neurosci Lett. 2016;630:45-52.

50. Sakabe T, Sakai K, Maeda $\mathrm{T}$, et al. Transcription factor scleraxis vitally contributes to progenitor lineage direction in wound healing of adult tendon in mice. J Biol Chem. 2018;293:5766-80

51. Kittaka H, Tominaga M. The molecular and cellular mechanisms of itch and the involvement of TRP channels in the peripheral sensory nervous system and skin. Allergol Int. 2017;66:22-30.

52. Laverdet B, Danigo A, Girard D, et al. Skin innervation: important roles during normal and pathological cutaneous repair. Histol Histopathol. 2015;30:875-92.
53. Cruzat A, Witkin D, Baniasadi N, et al. Inflammation and the nervous system: the connection in the cornea in patients with infectious keratitis. Invest Ophthalmol Vis Sci. 2011;52:5136-43.

54. Minnone G, De Benedetti F, Bracci-Laudiero L. NGF and its receptors in the regulation of inflammatory response. Int $\mathrm{J}$ Mol Sci. 2017;18:pii: E1028.

55. Peleshok JC, Ribeiro-da-Silva A, Peleshok JC, et al. Neurotrophic factor changes in the rat thick skin following chronic constriction injury of the sciatic nerve. Mol Pain. 2012;8:1.

56. Shi X, Wang L, Clark JD, et al. Keratinocytes express cytokines and nerve growth factor in response to neuropeptide activation of the ERK1/2 and JNK MAPK transcription pathways. Regul Pept. 2013;186:92-103.

57. Blanco-Mezquita T, Blanco-Mezquita T, Proença R, et al. Nerve growth factor promotes corneal epithelial migration by enhancing expression of matrix metalloprotease-9. Invest Ophthalmol Vis Sci. 2013;54:3880-90.

58. Hong J, Qian T, Le Q, et al. NGF promotes cell cycle progression by regulating D-type cyclins via PI3K/Akt and MAPK/Erk activation in human corneal epithelial cells. Mol Vis. 2012;18:758-64.

59. Katayama Y, Battista M, Kao WM, et al. Signals from the sympathetic nervous system regulate hematopoietic stem cell egress from bone marrow. Cell. 2006;124:407-21.

60. Martínez-Martínez E, Galván-Hernández CI, Toscano-Márquez B, et al. Modulatory role of sensory innervation on hair follicle stem cell progeny during wound healing of the rat skin. PLoS One. 2012;7:e36421.

61. Hayano S, Fukui Y, Kawanabe N, et al. Role of the inferior alveolar nerve in rodent lower incisor stem cells. J Dent Res. 2018;97:954961. (in press).

62. Nishida T. Neurotrophic mediators and corneal wound healing. Ocul Surf. 2005;3:194-202.

63. Saika S, Okada Y, Miyamoto T, et al. Role of p38 MAP kinase in regulation of cell migration and proliferation in healing corneal epithelium. Invest Ophthalmol Vis Sci. 2004;45:100-9.

64. Mikulec AA, Tanelian DL. CGRP increases the rate of corneal reepithelialization in an in vitro whole mount preparation. J Ocul Pharmacol Ther. 1996;12:417-23.

65. Chéret J, Lebonvallet N, Carré JL. et al. Role of neuropeptides, neurotrophins, and neurohormones in skin wound healing. Wound Repair Regen. 2013;21:772-88.

66. Dallos A, Kiss M, Polyánka H, et al. Effects of the neuropeptides substance $\mathrm{P}$, calcitonin gene-related peptide, vasoactive intestinal polypeptide and galanin on the production of nerve growth factor and inflammatory cytokines in cultured human keratinocytes. Neuropeptides. 2006;40:251-63.

67. Di Girolamo N, Sarris M, Chui J. et al. Localization of the lowaffinity nerve growth factor receptor p75 in human limbal epithelial cells. J Cell Mol Med. 2008;12:2799-811.

68. Radtke C, Rennekampff HO, Reimers K, et al. Paracrine loop of keratinocyte proliferation and directed neuritic outgrowth in a neuroepithelial coculture. Ann Plast Surg. 2013;70:162-7.

69. Matsuyama A, Takatori S, Sone Y, et al. Effect of nerve growth factor on innervation of perivascular nerves in neovasculatures of mouse cornea. Biol Pharm Bull. 2017;40:396-401.

70. Di G, Qi X, Zhao X, et al. Corneal epithelium-derived neurotrophic factors promote nerve regeneration. Invest Ophthalmol Vis Sci. 2017;58:4695-702.

71. Saika S, Shiraishi A, Liu CY, et al. Role of lumican in corneal epithelium during wound healing. J Biol Chem. 2000;275:2607-12.

72. Price TJ, Louria MD, Candelario-Soto D, et al. Treatment of trigeminal ganglion neurons in vitro with NGF, GDNF or BDNF: effects on neuronal survival, neurochemical properties and TRPV1-mediated neyropeptide secretion. BMC Neurosci. 2005:6; 4. https://doi.org/10.1186/1471-2202-6-4 
73. Nagano T, Nakamura M, Nakata $K$, et al. Effects of substance $P$ and IGF-1 in corneal epithelial burrier function and wound healing in a rat model of neurotrophic keratopathy. Invest Ophthalmol Vis Sci. 2003;44:3810-5.

74. Ceppa E, Cattaruzza F, Lyo V, et al. Transient receptor potential ion channels V4 and A1 contribute to pancreatitis pain in mice. Am J Physiol Gastrointest Liver Physiol. 2010;299:G556-571.
75. Nishida T, Makamura M, Ohfuji K, et al. Synergistic effects of substance $\mathrm{P}$ with insulin-like growth factor-1 on epithelial migration of the cornea. J Cell Physiol. 1996;169: $159-66$.

76. Garcia-Hirschfeld J, Lopez-Briones LG, Belmonte C. Neurotrophic influences on corneal epithelial cells. Exp Eye Res. 1994;59:597-605. 